\title{
The effect of the Theo van Gogh murder on house prices in Amsterdam
}

\author{
Pieter A. Gautier* Arjen Siegmann ${ }^{\dagger}$ \\ Aico Van Vuuren ${ }^{\ddagger}$
}

November 2006

\begin{abstract}
This paper estimates the impact of the murder of film maker Theo van Gogh on November 2, 2004, on listed house prices in Amsterdam with a unique dataset. We use an hedonic-market approach to show that general attitudes towards Muslim minorities were negatively affected by the murder. Specifically, we test for an effect on listed house prices in neighborhoods where more than $25 \%$ of the people belong to an ethnic minority from a Muslim country (type I). Relative to the other neighborhoods, house prices in type I neighborhoods decreased by on average 3\%, with a widening gap over time. The results are robust to several adjustments including changes in the control group. There is no significant difference in the time it takes for houses to be sold in type I versus other neighborhoods. Finally, people belonging to the Muslim minority were more likely to buy and less likely to sell a house in a type I neighborhood after the murder than before.
\end{abstract}

*Free University Amsterdam and Tinbergen Institute. Address: Department of Economics, Free University Amsterdam, De Boelelaan 1105, NL-1081 HV Amsterdam, The Netherlands, email: gautier@tinbergen.nl

${ }^{\dagger}$ Free University Amsterdam and Netherlands Central Bank, email: asiegmann@feweb.vu.nl

${ }^{\ddagger}$ Free University Amsterdam and Tinbergen Institute, email: vuuren@tinbergen.nl We would like to thank Christrian Dustmann and Jaap Abbring for discussions on earlier versions and participants at seminars at the Tinbergen Institute in Amsterdam, Université Paris I and Université de Toulouse. In addition, we would like to thank Nalan Basturk, Nora El-Hantali and Meltem Daysal for assistance. 


\section{Introduction}

The murder of columnist, tv-show host and film maker Theo van Gogh on November 2, 2004 in Amsterdam by a fundamentalist Muslim, had a huge impact on Dutch society. Figure 1 shows the number of Dutch newspaper articles per week that mentioned the murder. In the first two weeks, the murder was mentioned in almost 4,000 unique articles. Later spikes in attention coincide with the trial and conviction of the murderer (around week 30 of 2005), and the week one year after the murder (November 2005, week 45). Atteveldt et al. (2005) also give evidence of a strong peak in the joint occurrence of the words "Islam", "terror" and "immigration" on any page of a Dutch national newspaper. This peak in news coverage is in the same order of magnitude as the coverage of the 9-11 events in the Netherlands. ${ }^{1}$ Given the large effects of the murder of this public figure on Dutch society, the question in this paper is whether this event had a measurable effect on the attitudes towards Muslims in general. We test this with an hedonic-market approach.

Specifically, we compare list prices in Amsterdam neighborhoods with more than 25\% Moroccan and Turkish inhabitants (which we label type I neighborhoods) before and after the murder with house prices in the other (type II) neighborhoods. ${ }^{2}$ We also use alternative control groups that look more like the type I neighborhoods in terms of other characteristics. We find that after the murder, the difference in housing prices between type I and type II neighborhoods increased statistically significantly. We find that the relative house prices in type I neighborhoods decreased on average by about 1.5 percent in the year after the murder. Over time, the average decrease in the house prices is about 0.1 to 0.2 percent per week in the period after the murder. This negative impact stops after about 10 months resulting in a decrease of 4 percent in the type I neighborhoods.

We use a difference-in-difference (DID) approach to identify the impact of the murder. This approach has become very popular in labor and development economics. The only other paper that applies DID to the housing market is Abadie and Dermisi (2006). Many of the problems related to this method are less severe for the housing market. This is due to the fact that houses are fixed and

\footnotetext{
${ }^{1}$ The murder also drew a lot of media attention outside of the Netherlands, i.e. see a recent article by Kramer in the New Yorker of April 3, 2006.

${ }^{2}$ The largest groups of non-western immigrants are Surinam, Indonesian, Turkish and Moroccan. Even though the first two groups have their ethnic background from countries with a high concentration of Muslims, the concentration among immigrants in the Netherlands is low. In addition these groups are usually not associated with the other groups.
} 
cannot move between neighborhoods. Therefore, we do not have to worry about mobility between the treatment and control group (see for example Blundell and Costa-Dias, 2000). In addition, the murder can be regarded as an unanticipated and exogenous event. Difference-in-difference methods have often been applied to study policy changes where it is always questionable whether the policy changes are really exogenous. Still, serial correlation is a potential problem for reasons pointed out in (Bertrand, Duflo and Mullainathan, 2004). We deal with this in our robustness checks. Another fundamental problem in cross sectional neighborhood-effect studies is to distinguish between a neighborhood effect and the aggregation of individual effects: the so called reflection problem, see Manski (1993, 2000). However, we are not so much interested in identifying neighborhood effects but more in the effects of the Van Gogh murder (which can be treated as an unexpected event) on different neighborhoods.

Home ownership is typically very low among Muslim minorities. In 2002, owner-occupied housing was 57 percent among the ethnic Dutch in the Netherlands while for the Dutch-Moroccan it was 9 percent and for the Dutch-Turkish it was 20 percent (Sociaal en Cultureel Planbureau, 2005). In Amsterdam, those figures are lower. For the whole of Amsterdam, home ownership is only $20 \%$ while in the type I neighborhoods it is even smaller. We show that less than $5 \%$ of the people who sold their house in a type I neighborhood had a Moroccan or Turkish origin. Therefore, if house prices change in type I neighborhoods relatively to type II neighborhoods, we interpret this as a change in the common attitude towards type I neighborhoods and hence towards immigrants. We do find some evidence that the share of Turkish and Moroccan sellers decreased and the share of buyers increased relatively strongly in type I neighborhoods after the murder. This suggests that segregation increased.

Our findings can be explained by a standard hedonic market model, i.e. Tinbergen (1956) or Rosen (1974). The price of a house is determined by many attributes of which the composition of the neighborhood is just one. After the murder, the value of living in a type I neighborhood decreased relatively to living in a type II neighborhood for some agents. Since the inhabitants of the type I neighborhoods have nothing to do with the murder, one can interpret the drop in house prices as a negative externality. Recent evidence from the SCP (2006) suggests that relatively few individuals actually experience a change after the murder in their personal life but more than $80 \%$ believes that the murder affects the relationship between Muslims and non-Muslims in the Netherlands. Other studies have found that attitudes of the population towards immigrants are strongly based on perceptions. For example, it is widely believed that immigrants decrease 
wages and increase crime while there is often no or even opposite evidence for those claims, see Butcher and Piehl (1998), Card (2005) and Card et al. (2005). Glaeser (2005) shows that if some political groups have interest in spreading hatred towards other groups and there are small incentives to learn the truth, the hatred can be self-fulfilling. When house prices drop substantially, the incentives about learning the truth increase. However, house prices also have a speculative component which makes it less profitable to deviate from a common-belief market equilibrium that values houses in type I neighborhoods less than in type II neighborhoods even if one's private value towards living in type I neighborhoods have not changed.

There are a number of papers that study the cost of terrorism and conflicts. Abadie and Gardeazabal (2003) find substantial effects from the Basque terrorist conflict on the Basque Country. Glaeser and Shapiro (2002) find weak evidence that terrorism leads to less urbanization but they also argue that the causal link is dubious. Enders and Sandler (1991) and Fleischer and Buccola (2002) study the effect of terrorism on tourism and find mixed evidence. Dermisi and Abadie (2006) find that the 9-11 events still have an impact on office prices in high rise buildings in Chicago. Eckstein and Tsiddon (2004) argue that besides the lower life expectancy, Israel suffered a substantial drop in GDP per capita due to the high defense expenses to reduce terrorism. Frey et al. (2006) survey the literature on the economic impact of terror and claim that at the date they wrote their survey, no study has undertaken the hedonic market approach that we do in this paper.

Finally, we would like to emphasize that our paper also contributes to understanding the working of the housing market in general. In our duration analysis we estimate a mixed proportional hazard model allowing for unobserved heterogeneity and find that the hazard first increases and then after two quarters gradually decreases. The increasing part can be explained by learning, non-sequential search of the sellers (they wait until a number of buyers arrive) or the fact that sellers become desperate after some time, see Albrecht et al. (2005).

The paper is organized as follows. Section 2 introduces the data. Section 3 presents the empirical model. In Section 4 we present our results. We investigate the robustness of our results and test for duration effects in Section 5. Section 6 explains our findings with a simple hedonic model and Section 7 concludes. 


\section{Data}

The data are collected on a weekly basis from the largest online multi-listing service in the Netherlands called Funda which contains more than $70 \%$ of the supply of houses listed by real estate agents. This is the market share of the largest Dutch association of real estate agents (NVM), which sponsors the Funda website. For the Amsterdam region, it has a typical stock of 3700 houses for sale in any given week.

The start of our period of analysis is week 17 of 2004 and the end of our period is week 6 of 2006 (the murder was in week 45 of 2004). For every house we collect the address, zip code, the posted price (ask price), the surface of the house and other features (like a garage) that may increase the value of the house. In addition we have information on whether the house is conditionally sold. ${ }^{3}$ The posted price of the house represents the ask price by the seller and there are no legal restrictions in the Netherlands concerning this price and the characteristics that are posted at the website. Even though this may be interpreted as an important drawback of our analysis, there are no advantages for real-estate agents of giving inaccurate information on easily observable characteristics of the house because buyers always view the house before buying.

In order to investigate whether the price and/or the surface of a house differs from the actual price and surface, we use additional data from the Netherlands' Cadastre and Public Register Agency (Kadaster). This is a public agency that registers and sells the actual selling prices of all houses. Our data set contains all houses sold in the years 2004 and 2005 in Amsterdam. The number of observations equals 16,384 . Although for about $50 \%$ of the houses we have an indication about the week in which the conditional contract is signed (which is the date of agreement on the price), we are not able to verify this information as the Kadaster only registers the date at which the ownership of the house changes. Usually the house changes hands a couple of months after the actual date of agreement, but it is not uncommon that this takes more time. Hence, many of the houses at the end of our observation window may not have been registered as being sold in 2005. More information about this data set can be found in Section 5 .

We identify the date at which a house enters the market as the date it first appears on the Funda website. In our main analysis we identify the date a house leaves the market as the first week it does no longer appear at the website, conditionally on the observation that it does not re-appear. This implies that

\footnotetext{
${ }^{3}$ Conditionally sold implies that the buyer and seller arranged a contract but that the buyer still has the possibility to cancel the transaction due to financial incapabilities.
} 
we do not take account of the additional information on whether the house is conditionally sold. The problem with the latter variable is that different realestate agents use different strategies regarding the information that they provide to potential buyers. Some real estate agents do not provide this information since it might discourage bidders and these can be useful at the moment the transaction is canceled. It can be found that only 50 percent of the houses disappear from the website with an intermediate period in which it is conditionally sold. This is in contrast with common practice that private buyers of residential properties always use conditions in their contract. In addition, it is not uncommon that the buyer uses its right to cancel the transaction. We find that in 7 percent of the cases the house appears to be not sold after Funda reported it to be conditionally sold. Finally, we do not expect that our results are affected by the different definitions of the period at which a house is for sale since the average time the house is conditionally sold is relatively short. We find that the medium period in which the house is reported to be sold conditional on the event that this is reported equals 6 weeks. We expect this number to be an overestimate of the medium for all houses, since agents might be more likely to report the sold status when the contracted period is relatively long. We investigate this in our robustness checks in section 5 .

We have 328,711 price observations in the raw data set of which 328,449 are usable (48 prices were either below 10,000 or above 10,000,000 euro and 214 observations did not report surface). These price observations are recorded from 20,743 different houses (of which 6 turned out not to be usable). Table 1 lists the averages of the main variables that we use.

We linked the information about individual houses from the Funda website with neighborhood information from the statistics council in Amsterdam. ${ }^{4}$ In total there are 90 neighborhoods in Amsterdam which have residential property for sale. A typical neighborhood has 8,000 inhabitants. The most important neighborhood information that we use is the ethnic origin of the residents. As mentioned in the Introduction, we label neighborhoods as type I when the fraction of Turkish and Moroccan inhabitants exceeds 25\%, the other neighborhoods are labeled type II. ${ }^{5}$ We have in total 12 type I and 88 type II neighborhoods. Table 1 shows that the average price of a house in type I neighborhoods is around 180,000 euro. This is much lower than the average house price of 325,000 euro in the type II neighborhoods. We find that this can be partly explained by the observed characteristics of the houses, which are more favorable for the type II

\footnotetext{
${ }^{4}$ See http://www.os.amsterdam.nl, which provides a great number of statistics online.

${ }^{5}$ The fraction of other Muslim immigrants is negligible.
} 
neighborhoods: the houses in type I neighborhoods are smaller, more likely to be an apartment and less likely to have a garage. Houses are listed on average 20 weeks on the website in both types of neighborhoods. Not surprisingly, the income per head is much lower in the type I neighborhoods than in the type II neighborhoods. Finally we find that the crime rates, defined as the number of registered crimes divided by the number of individuals within the neighborhood, are lowest in the type I neighborhoods. This goes against the common perceptions since neighborhoods with many immigrants are usually believed to be more criminal. ${ }^{6}$ Our findings are in line with earlier research by Card (2005).

In order to obtain some ideas about the development of house prices in the two types of neighborhoods, Figure 3 shows the relative house prices per square footage. After the murder, houses in type 1 neighborhoods were slightly larger than before. This is also reflected in Figure 4, which illustrates the development of square footage over the observation window. Looking at the development in Figure 3 we find that the house prices were stable in the first half of 2004 while they increased strongly in the type II neighborhoods after that period. One potential reason for this strong increase is that the interest rates decreased a lot during this period. We investigate this in our empirical analysis in the next section.

Since we look at the differences in house prices between the type I and type II neighborhoods it is important that the ask price correctly reflects the situation at the housing market. If however, prices only adjust slowly, big changes in the inflow and outflow over time may occur just after the murder took place. This is not the case. Figure 5 shows the development of the number of houses that are posted for the first time in a given week. These figures do not indicate a large impact of the murder on the number of houses for sale over the period of analysis.

\section{Empirical approach}

The most general empirical setup is to specify the list price as a function of individual and neighborhood characteristics. Given that we are interested in the neighborhood effects from a given point in time, such a specification allows for including a cross term consisting of a type I dummy times a time effect. We use the following formulation:

$$
p_{i t}=\alpha+\beta x_{i}+\nu_{J(i)}+\mu(t)+\lambda(t) d_{J(i)}+\xi_{i}+\varepsilon_{i t},
$$

where $p_{i t}$ is the logarithm of the list price of house $i$ in week $t$. The function $J(i)$ maps the house into a particular neighborhood. The vector $x_{i}$ contains the

\footnotetext{
${ }^{6}$ Many of the drug-related crimes take place in the more expensive touristic neighborhoods.
} 
characteristics of the house, i.e. surface, the type (apartment, family home, etc.) and additional characteristics, such as whether there is a garage attached to the house. The variable $\nu_{J(i)}$ is a neighborhood fixed effect. The function $\mu(t)$ contains the time effects for all neighborhoods, while $\lambda(t)$ is a function of the additional time effects of the type I neighborhoods. The variable $d_{J(i)}$ is a dummy variable that equals one for a type I neighborhood and zero otherwise. The variable $\xi_{i}$ is a house fixed effect and $\varepsilon_{i t}$ is the residual term of house $i$ in period $t$. We assume that this residual term is independent and identically distributed with zero mean and variance equal to $\sigma^{2}$. This assumption can be criticized on the basis that sellers do not change house prices every week. We investigate this in Section 5.

For the remainder of our analysis we assume that there are $K$ houses, $T$ periods and $N$ different neighborhoods. The number of individual houses in a neighborhood in a particular time period equals $k_{j t}$.

This specification has been used in the literature before (see for example Abowd, Kramarz and Margolis (1999) for a labor market example). By estimating equation (1), the estimated $\lambda(t)$ would give the price effect over time of a house being for sale in a type I neighborhood versus a type II neighborhood.

Although the specification of (1) fits well with existing approaches to panel data in labor economics, in the case of house prices direct estimation is impossible since there is no mobility of houses between neighborhoods. Unlike a worker and his or her employment status, we cannot separate a house from its neighborhood, i.e., it is not possible to separately identify a house and a neighborhood fixed effect. One way to solve this problem is to take averages over the neighborhoods, measuring the treatment effect on the average ask price by neighborhood. ${ }^{7}$ That is also the approach we take in the rest of the paper which results in the following equation for $p_{j t}^{*}$, the average of the logarithm of the list price in neighborhood $j$ in period $t$

$$
p_{j t}^{*}=\alpha+\beta x_{j t}^{*}+\nu_{j}^{*}+\mu(t)+\lambda(t) d_{j}+\varepsilon_{j t}^{*},
$$

where $p_{j t}^{*}$ is the average price per neighborhood, i.e.,

$$
p_{j t}^{*}=\frac{1}{N_{j t}} \sum_{i \in H_{j}} x_{i} \cdot F S_{i t},
$$

and

\footnotetext{
${ }^{7}$ Another reason to take averages over neighborhoods is to reduce the impact of the independence assumption of $\varepsilon_{i t}$. As discussed in Section 5, house prices do not change on a weekly basis and this implies a correlation between $\varepsilon_{i t}$ with $\lambda(t)$ and $\mu(t)$. Taking averages reduces this problem since the i.i.d. assumption of $\varepsilon_{j t}^{*}$ is easier to defend. Still, serial correlation is a potential problem in our specification. We investigate this in Section 5 as well.
} 


$$
\begin{aligned}
F S_{i t} & = \begin{cases}1 & \text { if house } i \text { is for sale in period } t \\
0 & \text { otherwise, }\end{cases} \\
H_{j} & =\{i \mid \text { house } i \text { belongs to neighborhood } j\}, \\
N_{j t} & =\sum_{i \in H_{j}} F S_{i t} .
\end{aligned}
$$

Likewise, $x_{j t}^{*}$ is the vector of average properties for houses in neighborhood $j$ that are for sale at time $t$ :

$$
x_{j t}^{*}=\frac{1}{N_{j t}} \sum_{i \in H_{j}} x_{i} F S_{i t},
$$

The unobserved neighborhood fixed effect in this specification, $\nu_{j}^{*}$ includes both the original neighborhood fixed effect $\nu_{j}$ as well as the average of the individual fixed effects within a period and neighborhood. Note that it is assumed constant over time and this implies that systematic compositional changes in the unobserved fixed effects are not allowed in this specification. This is a necessary assumption for identification of the model. We discuss the impact of this independence assumption in Subsection 5.2.

An important choice to be made now is the specification of $\mu(t)$ and $\lambda(t)$, which measure the overall time effect, and type I neighborhood time effect, respectively. A straightforward approach is to use a fixed effects model that allows $\mu(t)$ and $\lambda(t)$ to vary each period. This results in estimates for $\mu(t)$ and $\lambda(t)$ for every week in the sample, where the estimates of $\lambda(t)$ after week 45 in 2004 measure the weekly impact of the murder. However, such an approach complicates the interpretation and typically leads to large standard errors. Hence, after doing the fixed effects estimation for $\mu(t)$ and $\lambda(t)$, we will assume a polynomial in terms of $t$ for both $\mu(t)$ and $\lambda(t)$. The polynomials parameterize the neighborhood effects in the affected and non-affected periods. Formally,

$$
\begin{aligned}
& \mu(t)=\pi(t)+\omega(t) d_{1 t}, \\
& \lambda(t)=\zeta(t)+\eta(t) d_{1 t},
\end{aligned}
$$

where $\pi(t), \omega(t), \zeta(t)$ and $\eta(t)$ are polynomials in $t$, and $d_{1 t}$ is a dummy variable that is equal to one for weeks after the murder and zero otherwise. $\pi(t)$ measures the overall time effect in all neighborhoods, and $\omega(t)$ the difference in timeeffect from the week of the murder onwards. $\zeta(t)$ measures the overall time effect in type I-neighborhoods, while $\eta(t)$ models the time varying effects in type Ineighborhoods in the weeks after the murder. Hence, when $\zeta(t)$ equals zero, we 
can interpret $\eta(t)$ as the impact of the murder on the house prices in the type I neighborhoods.

Even though we assume that the residual terms in equation (1) are independent and identically distributed, estimation of (2) using standard fixed effects is inefficient due to heteroskedasticity. There are two sources of heteroskedasticity: first there are different absolute price levels per neighborhood, the number of listed houses per neighborhood varies. Using logs reduces the first source while we use generalized least squares to correct for the latter effect. Basically, we weight neighborhoods by the inverse of the standard deviation of the dependent variable so neighborhoods with many observations typically receive a larger weight than neighborhoods with few observations. ${ }^{8}$

Note that our specification allows for possible learning effects. It is quite likely that the market only gradually learns about how housing prices are affected. Hence, only comparing two stages (one before and one after the news was announced) might understate the effect of the murder on market prices.

\section{Results}

We use a constant, linear and quadratic approximation of $\lambda(t)$ for all the empirical exercises in this paper. Our baseline results are in Table 2 and Figures 6 to 8. We include the fixed effects estimation of equation (2) in these figures in order to show the quality of our approximation methods. The first column of Table 2 shows the results when using a constant term. We find a significant negative price effect of 1.1 percent on the house prices in type I neighborhoods, see Figure 6.

As the fixed effects estimates in Figure 6 suggest, this is not due to a once and for all decrease. Column 2 of Table 2 shows the estimation results for the linear model, i.e., the parameters of the linear approximation to $\lambda(t)$. It shows that the development of house prices can be described quite well with a linear relationship. The impact is between 0.1 to 0.2 percent per week after the murder of Van Gogh and reaches a high of 3 percent a year after the murder. This suggests that there are either menu costs or there is a learning process in the market. We investigate this further in Section 5. Since house prices in type I neighborhoods were increasing before the murder and decreasing afterwards we believe that the trend effect is more informative than the constant effect. ${ }^{9}$

\footnotetext{
${ }^{8}$ Details of this method are provided upon request.

${ }^{9}$ Imagine that the treatment effects increase in each of the $n$ weeks before the treatment and decrease in each of the $n$ weeks after the treatment till the original level. Only looking at a constant would make one conclude that there is no effect.
} 
The results are visualized in Figure 7. In the third column of Table 2, we see that the estimates for a second degree polynomial are less precise. However, the parameters of the polynomial after the murder are still jointly significantly different from zero for both models, as the Wald statistics show. See Figure 8 for a graph of the results for the quadratic model. The estimation results for the control variables are as expected. The price of a house is increasing with size. Apartments and flats have a lower selling price than complete houses, while having a garage has a positive impact.

Note that we have a few months of earlier data on listed house prices, but they lack information on the presence of a garage. Using that data yields very similar results. In particular, it confirms the fact that before the murder, the trends in both neighborhoods was the same.

\section{Robustness checks and extensions}

In this section we investigate how robust our results are to changes in the underlying assumptions. We consider the effects of allowing for different impacts of the interest rate in different neighborhoods, investigate whether it is restrictive to assume that the neighborhood effects do not vary over time and that the error term is i.i.d.. Moreover, we show that our results are robust to taking different control groups; i.e. only consider type II neighborhoods where the average income per household is below 20,000 euros and we also use different definitions of type I neighborhoods; i.e. $10 \%$ and $40 \%$ people from a Moroccan or Turkish origin. In addition, we look at a specification using a continuous rather than a discrete measure of the affected neighborhoods.

We also look whether there are effects on the duration that a house was for sale, whether similar effects took place in Rotterdam, and we use data from the "Kadaster" on actual selling prices which allows us to compare the posted prices with the selling prices. Finally, we obtained information on names of sellers and buyers in the type I neighborhoods to investigate the origin and destination states of sellers and buyers in order to find out whether segregation increased.

\subsection{Investigation of the impact of the interest rate}

From Figure 3 it becomes apparent that our results are driven by the increase in the house prices in type II neighborhoods rather than a decrease in the house prices in the Type I neighborhoods. As we already mentioned before, this increase was likely due to decreasing interest rates together with the increase in 
the prospects of the Dutch economy. Essentially, this is not a problem for our analysis when we can expect the interest rate to have exactly the same impact on the house prices in the two types of neighborhoods. However, since the house prices and the income levels are different between the two types of neighborhoods, we would like to further investigate this. The data of mortgage interest rate are publicly provided by the Dutch Central Bank (See for example DNB, 2005). The frequency of these data is monthly and we use cubic splines to translate these into weekly mortgage interest rates. We use data of interest rates with fixed terms for up to 1 year, between 1 and 5 years, between 5 and 10 years and 10 years and over. Figure 9 illustrates the development of these interest rates over our observation window. We find that the interest rates are rather stable before the date of the murder, but decrease quite sharply the months following the murder.

In order to investigate the possible source of bias in our results due to different impacts of the interest rate on house prices in the two types of neighborhoods, we proceed by using a multiple step estimation routine. First, we estimate the fixed effects model as represented in for example Figure 6. Next, we regress the fixed effects on a flexible specification of the mortgage interest rates. The residuals of this regression can be interpreted as the impact of the murder after the difference in impacts of the interest rates between the neighborhoods have been taken out. As a final step we regress the residuals on a polynomial over time and in order to investigate the impact of the murder we allow for interaction effects with the date of the murder. Note that this procedure is very conservative in the sense that we prefer the interest rate explanation above the murder explanation in the analysis of the possible change in house prices between neighborhoods. It implies that the interest rate can pick up some effects of the murder but it is impossible that the murder can pick up some effects of the changes in the interest rate. An alternative would be to use the interest rates in equation (2) and report the difference-and-difference estimates directly. We found that this procedure did not produce different results from the baseline analysis.

The results of our regression of the fixed effects on the mortgage interest rates are reported in Table 3. The coefficients of this Table are somewhat difficult to interpret. In general, a minus sign implies that the house prices in type I neighborhoods are more sensitive to mortgage interest rate changes and a positive sign implies the opposite. However, the inclusion of multiple interest rates and the high level of multicollinearity between these regressors makes the interpretation difficult. The residuals of this regression are reported in Figure 10.

The results of the final step are listed in Table 4. We find that the single coefficient in the constant specification does not differ significantly from zero 
which implies that on average house prices in the type I neighborhoods did not decrease after the murder but again, this might be due to the fact that the interest rate picks up some of the murder-effect. Moreover, as we argued before the trend effect is more informative and we still find a negative and significant impact over time for both the linear and quadratic specification.

\subsection{Time independence assumption of the neighborhood fixed effects}

Our main identifying assumption is that the house fixed effects are independently distributed within a neighborhood through time. This implies that the unobserved characteristics of houses for sale within a neighborhood do not change in any systematic way. This assumption may be violated when proportionally more ill-maintained houses enter the market in a particular neighborhood. For our analysis this is a potential problem when it is occurs simultaneously with the date of the murder, which would lead us to mistakenly take a composition change of the houses before and after the murder as a change in house prices. ${ }^{10}$ One way to check the validity of our identifying assumption is by looking at the observed characteristics of the type I and type II neighborhoods and compare the development before and after the murder. With respect to the most important component: surface, we do not find that the average quality of houses for sale decreased in type I neighborhoods, see Figure 4. Note that surface and neighborhood together explain $80 \%$ of the variance in house prices. We therefore conclude that the composition of houses for sale in type I and type II neighborhoods did not change after the murder.

\subsection{Time dependence of the error term}

Another important assumption is that $\varepsilon_{i t}$, the error term in equation (2), is independent across individual houses as well as over time for a single house. Together with the trend effects $\mu(t)$ and $\lambda(t)$, the time-independence effect implies that prices of a single house can change every period. This is counterfactual since 70 percent of the listed houses never had a single price change. Table 5 gives more details and indicates that there is a strong relationship between the duration that a house is listed and the likelihood that the price is changed. This suggests that list prices are sticky, and that the disturbance term in (1), on which model (2) is based, is not independent over time.

\footnotetext{
${ }^{10}$ This situation would also indicate that something happened in the type I neighborhoods after the murder. However, these effects differ from our interpretation.
} 
To examine the potential impact of sticky list prices, consider a model that takes 'menu costs' into account. 'Menu costs' is the term used for costs associated with a change in the public price of a good, see Mankiw (1985). Whatever the nature of these costs, monetary or non-monetary, direct or indirect, the presence of costs makes sellers reluctant to change the listed price immediately in response to a change in the market price of the house. To model such an effect, define $\dot{p}_{i t}$ as the logarithm of the market price of house $i$ in period $t$ and assume the same specification for this house as in equation (1). In addition, denote the listed price by $p_{i t}$, and let $\rho$ be an arbitrary constant. We have

$$
p_{i t}=\alpha+\beta x_{i}+\nu_{J(i)}+\mu(\widetilde{t}(t))+\lambda(\widetilde{t}(t)) d_{J(i)}+\xi_{i}+\varepsilon_{i \widetilde{t}(t)}
$$

where $\widetilde{t}(t)$ is the time period of the last price change which is defined as

$$
\widetilde{t}(t+1)=\left\{\begin{array}{c}
\widetilde{t}(t) \text { if }\left(\left|P_{i t}-\dot{P}_{i t}\right|<\rho\right) \\
(t+1) \text { if }\left(\left|P_{i t}-\dot{P}_{i t}\right| \geq \rho\right)
\end{array}\right.
$$

Sellers only change their prices if the difference between the actual and the desired price is sufficiently large. If this is the case, then the price is updated towards the present market price. Note that the model is identical to our original model when $\rho=0$, whereas $\rho=\infty$ results in a model in which sellers never adjust their prices.

Now the question is whether this may cause potential problems when we want to use our model instead of the extended model presented here. Of course, estimation of equation (1) results in inconsistent estimates due to the correlation between the error term and the trend effects. However, we do not estimate this equation but instead estimate (2), using the averages over a neighborhood in a single period. Then, as long as there is no change in the composition of the durations of a single neighborhood over time, there is no correlation between the error term and the trend effects.

Still, it may be possible that a downward price shock in a neighborhood (like the murder) leads to no, or only small changes in the list price, and a longer duration of the time to sale. This may be caused by adaptive learning, or the reluctance of sellers to adjust the list price downwards due to nominal loss aversion, see Genesove and Mayer (2001). The possible duration effect is examined in Subsection 5.8, but first we consider a correction based on taking only list prices of houses in the first week that they appear online. Although the same problems as above may apply here, because sellers might be slow to 
adjust their expectations of the sales price to market developments, the effect will at least be less severe. Again, we exclude all houses listed before week 17 in 2004 (since these houses do not have records on the attachment of a garage), which leaves us with 11,951 observations. The results of the estimation with only first-week prices are given in Table 6 .

The results in Table 6 show that using first-week prices does not have a big impact on our results. The overall effects in the constant specification increase to 1.3 percent. For the linear specification we find an increase in the weekly loss in house prices.

\subsection{Choice of the control group}

The assumption underlying the neighborhood equation (2) is that the trend in list prices of houses in type I and type II neighborhoods share a common trend, $\mu(t)$. Under this assumption, the price difference after the murder, measured by $\lambda(t)$, correctly measures the structural price difference in the period after the Van Gogh murder. However, this leaves two questions unanswered. First, it is possible that there are other effects than the Van Gogh murder driving the results, i.e., demand and supply factors unrelated to the Van Gogh murder that impact the relative prices of houses in type II neighborhoods vis-à-vis the houses in type I neighborhoods. Second, one might argue that type I and type II neighborhoods are so different in population and type of housing, that it is hard to justify the existence of a common trend. Perhaps the two types of neighborhoods are separate housing markets that are each influenced by completely different factors. A third potential problem is that movements between type I and type II neighborhoods may not only decrease prices in the type I neighborhoods but may also increase the prices in the type II neighborhoods. This critique is also relevant for labor market evaluation studies, where it is necessary to assume that the impact of treatment does not affect the control group, see for example Heckman et al. (1999).

The first problem is present in all (DID) studies. The best we can do is control for other factors that might explain the relative price differentials between type I and type II neighborhoods.

The impact of the second problem can be evaluated by restricting the neighborhoods used for the analysis to those with an average net yearly income per head below 20,000 euros. This way, we leave out neighborhoods with large and expensive houses, for which different supply and demand effects might be relevant. The total number of neighborhoods is now equal to 59 and the number of 
type I neighborhoods is still equal to 12 . The yearly income per household is equal to 16,302 euros in type II neighborhoods, which is now close to the 16,408 euros for type I neighborhoods. The results of this analysis are reported in Table 7. The results in the table show that the estimate using the constant term is -1.3 percent, slightly higher than the baseline results in Table 2 .

The linear specification has a larger absolute value of the constant term but a slightly lower value of the linear coefficient. Another way to assess the validity of the definition of type I and type II neighborhoods is to analyze the behavior of buyers and sellers of Turkish and Moroccan origin. This is done in Section 5.11, where we conclude that the flow from type I to type II neighborhoods did not increase after the murder, but changed in composition.

The third problem is reduced whenever the control group is relatively large in comparison to the treatment group and when movements from type I to type II neighborhoods did not change over time. Especially in our baseline results the number of type II neighborhoods is large in comparison to the number of type I neighborhoods. In addition, we show in 5.11 that before the murder $23 \%$ of the non-immigrants ( $95 \%$ of total sales) moved from a type I to a type II neighborhood while this percentage was 24.1 after the murder. Hence, we can conclude that our results are not caused by a large flow of individuals who move from type I to type II neighborhoods.

\subsection{Continuous analysis of the treatment group}

In the previous subsections, we assumed that the treatment and control groups are determined by a discrete level of the percentage of Turkish and Moroccan originated inhabitants in a particular neighborhood. In this subsection, we investigate whether different levels in the degree of Turkish and Moroccan originated immigrants is also relevant. We rewrite equation 2 as follows

$$
p_{j t}^{*}=\alpha+\beta x_{j t}^{*}+\nu_{j}^{*}+\mu(t)+\lambda(t) \gamma(s)+\varepsilon_{j t}^{*},
$$

where $s$ is the percentage of Turkish and Moroccan originated immigrants and $\gamma$ is a function of $s$. Note that the original specification is a special case of this representation with $\gamma$ being a step function that jumps from zero to one when $s$ gets larger than 25 percent.

We use a polynomial representation for $\gamma$. The results of this exercise are presented in Table 8. We find that a higher density of Turkish and Moroccan immigrants increases the impact of the murder. However, in all of the specifications, the second order term is positive and hence having very many immigrants does 
increase the impact less than proportional. Table 9 presents the results when we use a piecewise constant specification rather than a polynomial. We find that the negative impact on the trend term is especially relevant when the percentage of Turkish and Moroccan immigrants increases from below 10 to above 10 percent. For higher percentages it stays stable up to 30 percent. It increases again above 30 percent. In order to illustrate the impact of the results listed in 8 and 9, we present the total impact after 13, 26 and 52 weeks in Figures 12, 13 and 14. We find that the patterns do not change that much from each other, but the total impact increases over time. Remarkable is the fact that the total impact after 52 weeks is much larger than we found before.

\subsection{Using information on conditional sale}

Until now, we have not used the information on the conditionally sold status of the properties that are listed on Funda, the multi-listing service (MLS). In this section we check the robustness of our results by assuming that the house is sold at the moment that it appears as conditionally sold on the website. The problem with using this assumption in the first place, is that a reported conditional sale is not necessarily reported for houses that are sold, i.e., it is the own initiative of the real-estate agent to publish such a message. Second, there might be a considerable time lag between the actual agreement between buyer and seller and the appearance of the conditional sold status. However, the advantage of using conditional sale information is that houses that are withdrawn from the listing service without being sold are discarded, and houses have no effect on the neighborhood average as soon as they are conditionally sold. The latter effect is especially important here, since some real-estate agents leave houses in the system for a number of weeks although they have a conditionally sold status. ${ }^{11}$

Table 10 presents the estimation results using only houses that ultimately experience a conditional sale. We find that the constant effect, - 0.8 percent, is slightly smaller than the 1.1 percent of the baseline estimation. However, the results for the linear trend change quite a lot, with a positive value for the constant term and an almost twice as large absolute value for the linear coefficient.

\subsection{Investigation of the impact of serial correlation}

As indicated in the introduction, our method does not suffer from many of the problems related to the use of difference-in-difference estimations. However, given

\footnotetext{
${ }^{11}$ This can be explained by real-estate agents using the MLS as a marketing tool for their firm.
} 
that the list price of a house does not change frequently, it is likely that the error term in the specification of $p_{j t}^{*}$ in (2) will be serially correlated. I.e., a large neighborhood mis-pricing (in terms of the specification in (2)) in one period is likely to carry over to the next period.

Betrand et al. (2004) point out that the standard errors from simple differencein-difference estimators can be biased when the number of periods is long, the dependent variable is likely to suffer from serial correlation and the treatment variable changes very little over time. Unfortunately, our analysis is potentially sensitive to all these factors. Therefore, it is important to investigate the possible impact of serial correlation on the standard errors of the estimates of $\lambda(t)$.

One possible way to correct for this is by using block bootstraps as suggested in Bertrand et al. (2004). Unfortunately, this method only works when the panel is balanced. In order to correct for this we use a balanced panel in our analysis, dropping those neighborhoods with fewer observations than time periods. This results in dropping 12 of the 90 neighborhoods.

Table 19 lists the results of the block bootstrap exercise. We basically sample neighborhood rows rather than time/neighborhood cells to obtain the empirical distribution of estimates and the "correct" t-values at the $5 \%$ level. The first three rows list the t-values when we drop the 12 neighborhoods. There are some small changes in comparison with the original results. In particular, the trend term in the second column has a lower t-value than for the original results in Table 2 . The rows below list the critical values found by the block bootstrap exercise. In the first column, we find that the critical values are much higher in absolute terms than those of a standard normal distribution. This suggests a big impact of serial correlation in the original results. Nevertheless, our conclusions are not affected since the estimated t-value is still higher than the critical t-values as listed in the table.

The second column suggests that the changes in critical values for the $t$-values are smaller. In addition, we find that our conclusions are again not affected.

\subsection{Duration analysis}

We have established a persistent negative price effect between type I and type II neighborhoods after the week of the Van Gogh murder. However, as noted in Section 5.3, the number of weeks it takes for a house to be sold gives additional information on the effect of the murder on the housing market. To test for duration effects, we use a mixed proportional hazard model with both duration and time dependence, see Van den Berg (2001). Let $\theta(t, \tau, x, v)$ be the (hazard) rate at 
which houses are sold. In this notation, $t$ is the duration in weeks that the house is on the multi-listing service, $\tau$ is calendar time as measured in weeks starting from the first week of 2004. The vector $x$ represents the observed characteristics of the house, just as in the earlier price equation (1). ${ }^{12}$ The variable $v$ represents the unobserved characteristics of the house. We use the following specification for the hazard rate

$$
\left.\theta\left(t_{i}, \tau_{i}, x_{i}, v\right)=\exp \left(x \beta+\nu_{J(i)} \gamma_{1}\left(\tau_{i}\right)+\gamma_{2}(\tau) d\right) \psi\left(t_{i}\right)\right) u_{i}
$$

where $\nu_{j}$ is a neighborhood fixed effect and, as before, $J(i)$ maps a house $i$ to its neighborhood $j=J(i)$. The function $\gamma_{1}$ represents the overall time effect, while $\gamma_{2}$ represents the additional effect for houses in type I neighborhoods. The function $\psi$ represents the duration dependence. For all functions we use a piecewise constant specification, see Lancaster (1990). We use a fixed mass point distribution for the stochastic variable $u_{i}$ and assume it to be independent and identically distributed among the observations. Since all houses that are for sale in the first week of the sample period are left-censored with respect to duration, we only include newly arrived houses after the first week of the sample period.

Estimation results for the mixed proportional hazard specification are listed in Table 11. As before, we do not list the levels of the neighborhood fixed effects. First of all, Table 11 shows that larger houses, apartments and houses with a garage attached sell faster. Houses have a relatively small probability to be sold in the first four weeks, while the highest probability to sell a house is in between weeks 9 and 13. In the second quarter the probability decreases somewhat but it is never as low as it is in the first four weeks. This indicates that sellers need some time to advertise their property or that sellers become more impatient when the house is already for sale for more than one month, see Albrecht et al. (2005). It also indicates that learning effects are important since even if a seller gets many offers from potential buyers in the first quarter (s)he may not sell the house because it may signal that the house is of good quality. Only after sellers learn about the quality of the house they start to accept bids of potential buyers.

An important result in Table 11 is that $u_{1}=0$, which means that unobserved heterogeneity is negligible.

The possible impact of the murder can be found by comparing the cross effects

\footnotetext{
${ }^{12}$ We choose not to include price itself in our analysis since we expect this variable to be correlated with the unobserved characteristics. There have been a number of attempts to correct for this (for example Rutherford et al. (2005), but these methods are not suitable for the present analysis. In our opinion only a full information maximum likelihood approach with the inclusion of a price and duration equation would solve this problem. However, such a method is more restrictive in terms of parameters.
} 
of time and type I neighborhoods in the quarters before and after the murder. This shows that after the Van Gogh murder, there is no significant increase in the expected time to sell a house in type I versus type II neighborhoods. To show how the probabilities of selling a house are related, Figure 15 shows the development of the probability to sell within the very first week. The probabilities for type I neighborhoods are always below those of type II neighborhoods. In addition, the probabilities are increasing over time for all neighborhoods, with a larger increase for type I neighborhoods. However, we should take into account that the standard errors of the difference, i.e., the time effects times the type I neighborhood effects in Table 11, are large.

Note that the present literature on the duration of house sales usually assumes a Weibull distribution for the baseline hazard of the mixed proportional hazards model, see Rutherford et al. (2005) and Zuehlke (1987). For example, Zuehlke concludes that there is no duration dependence for occupied houses while there is positive duration dependence for vacant houses. A drawback of the use of a Weilbull baseline hazards specification is that we cannot allow for duration dependence other than duration dependence that is monotonic, see Lancaster (1990). We find in our analysis that the duration dependence is not monotonic, so the use of a Weibull distribution would be inappropriate.

\subsection{Comparison with registered house prices}

An additional check on house price effects around the Van Gogh murder is to use actual transaction data. To this end, we purchased data from the 'Kadaster', the official register for residential property ownership and transactions in The Netherlands. The data provided gives the transaction price of all house transactions in Amsterdam for the year 2004-2005. We merge our data set with the data set of the register by street address and zip code, taking only those houses from the register that have appeared on Funda. Also, we deleted some of the matches that had either a remarkably low transaction price or a large deviation between list price and transaction price. ${ }^{13}$ We were able to match 10,479 out of 16,384 of the houses recorded to be sold in the period 2004-2005. Apart from our own removal of some awkward houses, there are a number of reasons why we were not able to match all houses: (i) the house was sold by an agent outside the NVM organization that is behind Funda or sold without being listed on Funda, (ii) the house was sold before February 2004, the start of the Funda data set, (iv)

\footnotetext{
${ }^{13}$ The houses we deleted had a selling price under 10,000 euros and we deleted the matches with deviations over 30 percent of the selling price. In total we deleted about 3 percent of the dataset.
} 
real-estate agents may have misspelled the street address when it comes to the addendum to the house number. In all, the houses listed on Funda account for $60 \%$ of all houses sold in Amsterdam in the period 2004-2005.

Some of the reasons listed above also hold for this data set but in addition to this, many of the unmatched houses were listed at the end of our observation window. This implies that these houses were not yet sold in 2005, which is the end of the observation window for the registered database.

The average differences between house prices in the final week that the house is listed on Funda and the actual transaction price are reported in Table 12. The list prices presented are lower than those in Table 1 because here we only take the price in the final week of listing, whereas Table 1 considers the list prices for all houses in the weeks that they are listed. Also, the houses that are matched have a slightly lower house price than those we were not able to match. The mean transaction price for all recorded transactions is 285,213 euros. The entry 'discount' in Table 12 represents the percentage difference between the finally posted and the transaction price, and is $4.17 \%$ for all houses, $3.82 \%$ for houses in type I neighborhoods, and $4.23 \%$ for type II houses. In addition, the correlation between posted and transaction price is over 99\%, implying that the list price is a good representation of the ultimate transaction price.

Figure 16 displays the level of the average discount per neighborhood over time. As can bee seen in the Figure, there is a sharp increase in the average discount for houses in type I neighborhoods right after the week of the Van Gogh murder. This effect is in line with the 'menu costs' hypothesis, i.e., list prices do not drop immediately although market (transaction) prices do. Using the difference-in-difference estimate of this increase we find a point estimate of 1.4 percent with a standard deviation of 1.2 percent. Hence, even though the increase in the discount is large, it is not significant.

\subsection{Comparison with Rotterdam}

If Amsterdam house prices have indeed reacted to the Van Gogh murder in the way we postulate in this paper, a follow-up question would be whether house prices in other cities decreased as well. I.e., some of the neighborhoods labeled type I are geographically quite far from the location at which Theo van Gogh was murdered. Add to this the nationwide publicity and anxiety that this event had caused, and one would expect to see effects in other cities as well. In order to investigate this, we performed the same analysis for the city of Rotterdam as we did for Amsterdam. Rotterdam is quite comparable to Amsterdam in population, 
although it inhabits more immigrants and low income households. The results of the exercise are reported in Figure 17. From this figure we see no direct effect of the murder. We do see that house prices in type I neighborhoods fall relatively to those of type II neighborhoods starting around week 10 after the murder. However, we also repeated our difference-in-difference estimates for Rotterdam and we do not find such an unambiguous effect of the murder like in Amsterdam. ${ }^{14}$

\subsection{Who sells their house?}

The preceding results suggest a negative impact of the murder on the price in type I neighborhoods. There may be a number of reasons for this negative impact. First, it may be possible that Dutch homeowners sold their houses after the murder to Turkish or Moroccan immigrants. Since these immigrants usually have lower income, this may have caused the drop in house prices. Second, it may be possible that Dutch homeowners sold their houses to other Dutch homeowners. This implies that there is a lower valuation after the murder since the selling price decreases.

We investigate these issues in this subsection by looking at the origin of the buyers and the sellers. We collected additional data from the register agency about the names and addresses of those individuals who either bought or sold a house in the type I neighborhoods. We are able to find the origin of the seller by the investigation of the name. ${ }^{15}$ For each individual we have two addresses: one at the moment of the transaction and the most recent address. For buyers, the most recent address is typically the address of the house of the transaction involved, while the address at the date of transaction is interpreted as the original address. For sellers, we interpret the most recent address as the destination address.

As a first investigation we report the fraction of Turkish and Moroccan buyers and sellers in Table 13 for the type I neighborhoods and in Table 14 for the type II neighborhoods. We find that $9.3 \%$ of the buyers are from Turkish or Moroccan origin while among sellers this fraction is only $4.3 \%$. Even though these figures do not come from the stock of homeowners in the type I neighborhoods, it supports our conjecture that the fraction of homeowners is low for this group. It also indicates that the large changes in house prices we found in our previous results are mainly driven by changes in the preferences of Dutch rather than Turkish or Moroccan homeowners. Not surprisingly, the fractions are even lower for the type II neighborhoods. We also look at the fractions before and after the murder.

\footnotetext{
${ }^{14}$ The estimates are available on request.

${ }^{15}$ There are very typical names for either Turkish and Moroccans. We asked two assistants from both countries to find the names originating from these countries.
} 
We find that the fraction of Turkish or Moroccan buyers increased. This suggests that there was a drop in the number of native buyers while Turkish or Moroccan buyers increased their willingness to buy in these neighborhoods because of the drop in prices. We have to be careful however because a similar pattern is found in type II neighborhoods albeit smaller. If we take the "difference in differences" between the fraction of Turkish and Moroccan buyers in type I and II before and after the murder we see a relative increase of Turkish and Moroccan buyers in type I neighborhoods after the murder $(t=1.5)$ and a decrease in the sellers, $(t=-0.8)$.

We report the origin and destination states of buyers and sellers in Tables 15 to 18 before and after the murder. Those Tables suggest the following. Relatively less Turkish and Moroccan buyers of houses in type I neighborhoods came from type II neighborhoods after the murder and more came from outside of Amsterdam. A natural explanation is that the Turkish or Moroccan inhabitants outside Amsterdam felt more isolated after the increased negative sentiments and choose to move to Muslim neighborhoods, thereby increasing segregation. Another explanation is that the drop in house prices made the these neighborhoods more attractive for the Turkish and Moroccan homeowners. It is also possible that the fraction of non-Turkish or Moroccan originated sellers that left Amsterdam after the murder increased in the Type I neighborhoods. We cannot confirm those explanations because we also see that a larger share of the Turkish and Moroccan buyers of houses in type II neighborhoods came from outside Amsterdam after the murder and a smaller share came from type I neighborhoods.

If we look at the sellers destination states, we see that after the murder more Turkish and Moroccan sellers of houses in type I neighborhoods stay in type I neighborhoods while less Turkish and Moroccan sellers of houses in type II neighborhoods stay in type II neighborhoods, most of them move to outside Amsterdam.

The evidence suggests that after the murder there was more segregation since relatively more Turkish and Moroccan buyers bought a house in a type I neighborhood and fewer sold a house in a type I neighborhood after the murder.

\subsection{Direct evidence on attitudes}

Finally, we present some direct evidence on the attitudes about Muslims and the relation between Moroccan and Turkish Dutch citations and the native Dutch citizens. This evidence come from the LIS (Living situation non-native city inhabitants) questionnaire which was accidently held in the week after the murder, 
see SCP (2006). At the end of the questionnaire some additional questions were asked about expected attitude shifts after the murder. Of the native Dutch respondents, $33 \%$ personally thinks differently about the relation between Muslims and non-Muslims after the murder while $86 \%$ believes that the murder will have an effect on the relationship between Muslims and non-Muslims. Only 5\% believes that the murder will have an effect on themselves or their family. The latter fraction is a lot larger under Moroccans (20\%) and Turkish (13\%) Dutch inhabitants. This evidence is complementary to our indirect evidence of a shift in attitudes. Both approaches suggest that the murder had an impact on the expected relationship between Muslims and non Muslims.

\section{An hedonic market explanation for our find- ings}

Our empirical analysis showed that after the murder, (i) the house prices in type I neighborhoods decreased relative to those in type II neighborhoods, (ii) less than $5 \%$ of the sellers and buyers in type I neighborhoods were from Turkish or Moroccan origin, (iii) after the murder, the fraction of Turkish and Moroccan buyers increased, (iv) most people believe that the murder changes the relationship between Muslims and non-Muslims but few people believe that it affects their day-to-day live. Those findings can be explained by a standard hedonic market model, see Tinbergen (1956) and Rosen (1974) .

According to this view, a house is a commodity that consists of many attributes like size, neighborhood and the number of rooms. Following Rosen (1974) we can describe those attributes by a vector, $z=\left(z_{1}, \ldots, z_{n}\right)$ where each attribute has a value which we do not observe directly but we do observe the market price, $p(z)=p\left(z_{1}, \ldots, z_{n}\right)$ as given. This price is the result of a set of "kissing" offer and expenditure curves of sellers and buyers with different tastes. In this framework, we can interpret the murder of Theo van Gogh and the enormous media attention as follows. Suppose that there is a shock that makes it less attractive to live in type I neighborhoods for some individuals. They would be willing to pay even more to live in a type II neighborhood. Since $p\left(z_{1}, z_{2}^{*} \ldots, z_{n}^{*}\right)$ is really an envelope of value functions from potential buyers and offer functions from potential sellers, the price for houses in type II neighborhoods will go up. From our data we cannot infer whether this is due to the fact that seller's offer curves and or the buyers value functions change. Both result in a similar outcome. The difference between the average price in type II and type I neighborhoods increases.

Since houses have a speculative component things are more complicated than 
this. An individual might be perfectly happy in a type I neighborhood but if she believes that a large fraction of the market values type I-neighborhoods less after the murder she will also be more reluctant to move to a type I neighborhood. In other words, if there are $J$ potential buyers, $\theta^{1}\left(z_{1}, z_{2}^{*} \ldots, z_{n}^{*}\right), \theta^{2}\left(z_{1}, z_{2}^{*} \ldots, z_{n}^{*}\right)$, $\ldots \theta^{J}\left(z_{1}, z_{2}^{*} \ldots, z_{n}^{*}\right)$ will all depend on each other.

We can conclude the following. The murder made houses in type II neighborhoods relatively expensive. It shifted the value and or offer curves of some individuals towards type II neighborhoods. Since the majority of buyers and sellers were non Turkish or Moroccan Dutch, the effects we find is mainly caused by a preference shift for those groups. Since many people believe the Murder had an affect on the attitude towards Muslims but few people believe that it affects their own situation, it is likely that this shift mainly reflects a perceived shift of preferences of future buyers and sellers. The relative drop in prices for the type I attribute increased the fraction of Turkish and Moroccan sellers who remained in type I neighborhoods from about 2.5 to $5 \%$. The preference shift is likely to be smaller for this group. The fact that the total number of transactions in the market did not increase is not inconsistent with this story. There are many idiosyncratic shocks which cause people to either buy or sell a house like family or labor market changes. On average they will not affect the market price but they do influence the number of transactions. The murder of Theo van Gogh was more of an aggregate shock which did not cancel out across households and therefore did affect prices. The number of people that changed houses because of this shock just appeared to be small relative to those who move because of idiosyncratic reasons. Turkish or Moroccan buyers may have benefited from the price decrease if their preferences have not shifted after the murder. This would explain why they bought more houses in type I neighborhoods.

\section{$7 \quad$ Final remarks}

The economic impact of terrorism is in general difficult to measure. In this paper we take an hedonic-market approach and show that after the Murder of film maker and journalist Theo van Gogh, house prices in neighborhoods with more than $25 \%$ Muslims decreased with about 0.1 to 0.2 percent per week relatively to the other neighborhoods in Amsterdam. After about a year, the difference in trends stops and market sentiments cool down. On average, the price drop is about 1.5 percent while after a ten months it is 3 percent. We do not find evidence that the time it takes to sell a house in those neighborhoods increased relatively to our control neighborhoods after the murder. Those results turn out 
to be robust.

\section{References}

Abadie, A. And J. Gardeazabel (2003), The economic cost of conflict: A case study of the Basque country, American Economic Review 93, 113-32.

Abowd, J.M., F. Kramarz and D.N. Margolis (1999), High wage workers and high wage firms, Econometrica 67, 251-334.

Albrecht, J., A. Anderson, E. Smith, and S. Vroman (2005), Opportunistic Matching in the Housing Market, mimeo Georgetown University.

Atteveldt W., N. Ruigrok, J. KleinniJenhuis (2005), Associative framing, mimeo Free University Amsterdam.

Bertrand, M., E. Duflo and S. Mullainathan (2004), How much should we trust difference in difference estimates, Quarterly Journal of Economics, 74, 163-177.

Blundell, R. and M. Costa-Dias (2000), Evaluation methods for nonexperimental data, Fiscal Studies, 21, 427-468.

Butcher, K. And A.M. Piehl (1998), Recent immigrants: Unexpected implications for crime and incarceration, Industrial and Labor Relations Review, $51,654-79$.

CARD, D (2005), Is the new immigration really so bad?, IZA discussion paper 1119, forthcoming in Economic Journal.

Card, D., C. Dustmann and I. Preston (2005), Understanding attitudes towards immigration: the migration and minorities module of the first European social survey, Cream DP 3/05.

DNB (2005), Statistisch Bulletin, december 2005, DNB, Amsterdam.

Eckstein, Z. AND D. Tsiddon (2004), Macroeconomic consequences of terror: Theory and the case of Israel, Journal of Monetary Economics, 51:5, 9711002.

Enders W. AND T. SANDler (1991), Causality between transnational terrorism and tourism: the case of Spain, Terrorism 14(1) 49-58.

Frey, B. S. , S. Luechinger And A. Stutzer (2006). Calculating Tragedy: Assessing the Costs of Terrorism, Journal of Economic Surveys, forthcoming.

Fleischer, A. And S. Buccola (2002), War, Terror and the tourism market in Israel, Applied Economics 34(11), 1335-1343.

Genesove, D. And Mayer (2001), Loss Aversion and Seller Behavior: Evidence from the Housing Market, Quarterly Journal of Economics, 116(4), 12331260 . 
Glaeser, E.L. (2005), The political economy of hatred, Quarterly Journal of Economics, 120(1), 45-86.

Glaeser, E.L. And J.M. Shapiro (2002), Cities and warfare: The impact of terrorism on urban form, Journal of Urban Economics 51(2), 205-24.

Heckman, J.J., R.J. Lalonde and J.A. Smith (1999), The economics and econometrics of active labor market programs, in: O.C. Ashenfelter and D. Card, Handbook of labor economics, Volume 3A, North-Holland, Amsterdam.

Kramer, J. (2006) The Dutch model: Multiculturalism and Muslim immigrants, The New Yorker, April 3.

Lancaster, T. (1990) The analysis of transition data. New York: Cambridge university press.

Mankiw N.G. (1985), Small Menu Costs and Large Business Cycles: A Macroeconomic Model of Monopoly, Quarterly Journal of Economics, 100(2), 529-537.

MAnski C. (1993), Identification of endogenous social effects: the reflection problem, Review of Economic Studies, 60, 531-542.

MAnski C. (2000), Economic analysis of social interactions effects, Journal of Economic Perspectives, 14, 115-136.

Rosen, S. (1974), Hedonic prices and implicit markets: product differentiation in pure competition, Journal of Political Economy, 82(1), 34-55.

Rutherford, R.C., T.M. Springer And A. Yavas (2005), Conflicts between principals and agents: evidence from residential brokerage, Journal of Financial Economics, 76, 627-665.

SCP (2006), Year rapport integration 2005.

Tinbergen, J. (1956), On the theory of income distribution, Weltwirtschafliches Archiv, 77(2), 155-73.

Sociaal en Cultureel Planbureau (2005), Jaarraport integratie, Internetbijlagen hoofdstuk 8.

VAn den Berg, G.J. (2001), Duration Models: Specification, Identification, and Multiple Durations, Handbook of Econometrics, 5, 3381-3460. North-Holland.

Zuehlke, T. (1987), Duration dependence in the housing market, Review of Economics and Statistics, 69, 701-709. 


\section{Appendix A: Tables and Figures}

\section{Table 1: Descriptive statistics}

This table gives the descriptive statistics of the list prices collected. 'Sold' is the variable that signals whether a house is conditionally sold. The crime rate per neighborhood is derived from the Amsterdam statitistics council and includes ...

\begin{tabular}{|c|c|c|c|}
\hline Variable & $\begin{array}{c}\text { Number of } \\
\text { observations }\end{array}$ & Mean & $\begin{array}{l}\text { Standard } \\
\text { deviation }\end{array}$ \\
\hline \multicolumn{4}{|l|}{ All neighborhoods } \\
\hline Number of neighborhoods & 90 & & \\
\hline List price & 20148 & 290487 & 236261 \\
\hline Apartment & 20148 & 0.85 & \\
\hline Surface in square footage & 20148 & 1050 & 655 \\
\hline Garage attached & 18475 & 0.028 & \\
\hline Sold & 23656 & 0.177 & \\
\hline Surface (area) & 6557 & 1153 & 2281 \\
\hline Duration listed & 20148 & 20.36 & 18.71 \\
\hline Income per individual in neighborhood & 20148 & 20471 & 4459 \\
\hline Crime rate in neighborhood & 20148 & 0.148 & 0.268 \\
\hline \multicolumn{4}{|l|}{ Type I neighborhoods } \\
\hline Number of neighborhoods & 12 & & \\
\hline Price & 2497 & 175732 & 56533 \\
\hline Apartment & 2497 & 0.93 & \\
\hline Surface in square footage & 2497 & 804.6 & 265.4 \\
\hline Garage attached & 2278 & 0.018 & \\
\hline Surface (area) & 817 & 958 & 2347 \\
\hline Duration listed & 2278 & 20.83 & 20.34 \\
\hline Income per individual in neighborhood & 2278 & 16480 & 918 \\
\hline Crime rate in neighborhood & 2278 & 0.087 & 0.014 \\
\hline \multicolumn{4}{|l|}{ Type II neighborhoods } \\
\hline Number of neighborhoods & 78 & & \\
\hline Price & 17651 & 306721 & 247260 \\
\hline Apartment & 17651 & 0.839 & \\
\hline Surface in square footage & 17651 & 1084 & 686 \\
\hline Garage attached & 16197 & 0.029 & \\
\hline Surface (area) & 5740 & 1181 & 2271 \\
\hline Duration listed & 17651 & 20.16 & 17.92 \\
\hline Income per individual in neighborhood & 17651 & 21037 & 4472 \\
\hline Crime rate in neighborhood & 17651 & 0.157 & 0.285 \\
\hline
\end{tabular}




\section{Table 2: Baseline results}

This table shows the baseline results for the price effects of the Theo van Gogh murder. The first column lists the estimation results for the specification of $\lambda(t)=c$. The second and third column list the estimation results for the linear and quadratic specification, respectively. Panel A gives the difference-indifference estimates. Panel B to D show the estimation results for the general price effect before the murder, before the murder in type I neighborhoods, and after the murder. The variables $\eta, \pi, \zeta$, and $\omega$ refer to the variables defined in Equation (8).

\begin{tabular}{llll}
\hline \hline & I & II & III \\
\hline \hline
\end{tabular}

A: Difference-in-difference estimators

$\begin{array}{lccc}\text { Constant } & -0.0113 & -0.0030 & -0.0101 \\ & (0.00201) & (0.00382) & (0.00560) \\ t & \cdot & -0.0013 & -0.0023 \\ & & (0.00020) & (0.00078) \\ t^{2}(\mathrm{x} 100) & \cdot & -0.0047 \\ & \cdot & & (0.00256)\end{array}$

Other results

B: Results before the murder

$\begin{array}{lccc}\text { Constant } & 11.6299 & 11.6289 & 11.6300 \\ & (0.02281) & (0.02286) & (0.02281) \\ t(\mathrm{x} \mathrm{100)} & \cdot & -0.0000 & -0.0002 \\ & & (0.00007) & (0.00024) \\ t^{2} & \cdot & \cdot & 0.0006 \\ & & & (0.00087)\end{array}$

C: Results before the murder, type I neighborhoods

$t$

$t^{2}(\mathrm{x} 100)$

$0.0006 \quad-0.0005$

$(0.00019) \quad(0.00068)$

0.0044

(0.00250)

D: results after the murder

$\begin{array}{lccc}\text { Constant } & 0.0259 & 0.0007 & -0.0012 \\ & (0.00070) & (0.00134) & (0.00196) \\ t & \cdot & 0.0010 & 0.0009 \\ & & (0.00007) & (0.00027) \\ t^{2}(\mathrm{x} 100) & \cdot & -0.0009 \\ & & & (0.00089)\end{array}$

Control variables

$\begin{array}{lccc}\text { Surface } & 0.0924 & 0.0933 & 0.0933 \\ & (0.0011) & (0.00108) & (0.00108) \\ \text { Surface }^{2} \text { (x 1000) } & -0.011 & -0.012 & -0.012 \\ & (0.0003) & (0.0003) & (0.0003) \\ \text { Apartment } & -0.1067 & -0.1144 & -0.1141 \\ & (0.0070) & (0.0068) & (0.0069) \\ \text { Garage } & 0.1087 & 0.0840 & 0.0832 \\ & (0.0136) & (0.0132) & (0.0132)\end{array}$

Goodness of fit measures

$\begin{array}{llcc}R^{2} \text { within } & 0.65218 & 0.6707 & 0.6708 \\ R^{2} \text { between } & 0.8154 & \cdot & \cdot \\ R^{2} \text { overall } & 0.8324 & 0.8362 & 0.8367\end{array}$




\begin{tabular}{lr}
\hline \hline \multicolumn{1}{c}{ Variable } & \multicolumn{1}{c}{ Estimate } \\
\hline \hline Constant & $(0.6460$ \\
& \\
Logarithm of the interest rate & \\
& 0.2731 \\
Up to 1 year & $(0.0479)$ \\
& -0.9538 \\
Between 5 and 10 years & $(0.1782)$ \\
& 0.8358 \\
Over 10 years & $(0.098)$ \\
& \\
Logarithm of the interest rate - One pe- \\
riod lagged
\end{tabular}

Table 3: Regression of fixed effects on the mortgage interest rates 


\begin{tabular}{llll}
\hline \hline & I & II & III \\
\hline \hline
\end{tabular}

\section{Difference-in-difference estimators}

$\begin{array}{lrrr}\text { Constant } & 0.0019 & -0.0026 & -0.0117 \\ t(\mathrm{x} 100) & (0.0016) & (0.0026) & (0.0038) \\ & & -0.0891 & -0.2541 \\ t^{2}(\mathrm{x} 100) & (0.014) & (0.0543) \\ & & & -0.0070 \\ & & & (0.0018)\end{array}$

\section{Other results}

Results before the murder
Constant
$-0.0013$
$-0.0233 \quad 0.0386$
$t(\mathrm{x} 100)$
$\begin{array}{lll}(0.0013) & (0.0042) \quad(0.0171)\end{array}$
$-0.0698-0.3507$
$t^{2}(\mathrm{x} 100)$
$(0.0129) \quad(0.1134)$
0.0067
$(0.0018)$

Table 4: Results taking account of different impacts of the development in mortgage interest rates. 


\section{Table 5: List price changes}

For each interval in weeks of the duration of the house, this table give the number of houses and the percentage of houses that experience a change in list price during the time of listing.

\begin{tabular}{lrr}
\hline \hline \multicolumn{1}{c}{ Duration } & Number of observations & Percentage price change \\
\hline \hline & & \\
1-5 weeks & 2970 & 25.9 \\
$5-10$ weeks & 4097 & 5.9 \\
$10-15$ weeks & 2961 & 16.1 \\
$15-20$ weeks & 2182 & 27.4 \\
$20-25$ weeks & 1558 & 40.2 \\
$25-30$ weeks & 1270 & 51.7 \\
$30-35$ weeks & 761 & 54.5 \\
$35-40$ weeks & 458 & 61.6 \\
$40-45$ weeks & 342 & 64.6 \\
$45-50$ weeks & 263 & 73.4 \\
$50-55$ weeks & 1030 & 72.3 \\
& & \\
\hline \hline
\end{tabular}




\section{Table 6: First-week prices}

This table shows the baseline results for the neighborhood-effects of the Theo van Gogh murder using only the list prices in the first week that a house is listed. The first column lists the estimation results for the specification of $\lambda(t)=c$. The second and third column list the estimation results for the linear and quadratic specification, respectively. Panel A gives the difference-in-difference estimates. Panel B to D show the estimation results for the general price effect before the murder, before the murder in type I neighborhoods, and after the murder. The variables $\eta, \pi, \zeta$, and $\omega$ refer to the variables defined in Equation (8).

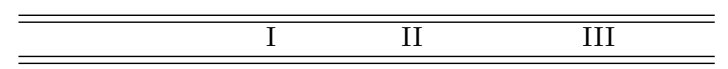

\section{A: Difference-in-difference estimators}

$\begin{array}{lccc}\text { Constant } & -0.013 & -0.001 & -0.001 \\ & (0.004) & (0.008) & (0.011) \\ t & \cdot & -0.005 & -0.012 \\ & & (0.002) & (0.007) \\ t^{2} & \cdot & \cdot & -0.001 \\ & & & (0.001)\end{array}$

Other results

B: Results before the murder

$\begin{array}{cccc}\text { Constant } & 11.678 & 11.687 & 11.687 \\ & (0.023) & (0.024) & (0.023) \\ t & \cdot & 0.000 & -0.001 \\ & & (0.001) & (0.002) \\ t^{2} & \cdot & \cdot & 0.000 \\ & & & (0.000)\end{array}$

C: Results before the murder, type I neighborhoods

$\begin{array}{cccc}t & \cdot & 0.003 & -0.002 \\ & & (0.002) & (0.006) \\ t^{2} & \cdot & 0.001 \\ & & & (0.001)\end{array}$

D: Results after the murder

$\begin{array}{lccc}\text { Constant } & 0.031 & -0.000 & -0.005 \\ & (0.001) & (0.003) & (0.004) \\ t & \cdot & 0.004 & 0.004 \\ & & (0.001) & (0.002) \\ t^{2} & \cdot & \cdot & -0.000 \\ & & & (0.000)\end{array}$

Control variables

$\begin{array}{lccc}\text { Surface } & 0.001 & 0.001 & 0.001 \\ & (0.000) & (0.000) & (0.000) \\ \text { Surface }^{2} & -0.000 & -0.000 & -0.000 \\ & (0.000) & (0.000) & (0.000) \\ \text { Apartment } & -0.159 & -0.188 & -0.186 \\ & (0.014) & (0.013) & (0.013) \\ \text { Garage } & 0.113 & 0.090 & 0.088 \\ & (0.026) & (0.025) & (0.025)\end{array}$




\section{Table 7: Income-per-head as neighborhood selection criterion}

This table shows the baseline results for the neighborhood-effects of the Theo van Gogh murder, defining type I neighborhoods as neighborhoods where the yearly income per head is below 20,000 euro. The first column lists the estimation results for the specification of $\lambda(t)=c$. The second and third column list the estimation results for the linear and quadratic specification, respectively. Panel A gives the diff-in-diff estimates. Panel B to D show the estimation results for the general price effect before the murder, before the murder in type I neighborhoods, and after the murder. The variables $\eta, \pi, \zeta$, and $\omega$ refer to the variables defined in Equation (8).

\begin{tabular}{llll}
\hline \hline I & II & III \\
\hline
\end{tabular}

\section{A: Difference-in-difference estimators}

$\begin{array}{lccc}\text { Constant } & -0.0134 & -0.0054 & -0.0124 \\ & (0.00241) & (0.00466) & (0.00685) \\ t & \cdot & -0.0009 & -0.0015 \\ & & (0.00025) & (0.00096) \\ t^{2}(\mathrm{x} 100) & \cdot & -0.0038 \\ & \cdot & & (0.00314)\end{array}$

Other results

B: Results before the murder

$\begin{array}{lccc}\text { Constant } & 11.5249 & 11.5344 & 11.5393 \\ & (0.02316) & (0.02332) & (0.02328) \\ t(\mathrm{x} \mathrm{100)} & \cdot & 0.0003 & -0.0003 \\ t^{2} & \cdot & (0.00011) & (0.00040) \\ & & \cdot & 0.0022 \\ & & & (0.00147)\end{array}$

C: Results before the murder, type I neighborhoods

$$
\begin{array}{cc}
0.0004 & -0.0004 \\
(0.00023) & (0.00084) \\
\cdot & 0.0032 \\
& (0.00307)
\end{array}
$$

$t^{2}(\mathrm{x} 100)$

D: Results after the murder

$\begin{array}{lccc}\text { Constant } & 0.0284 & 0.0034 & 0.0014 \\ & (0.00116) & (0.00221) & (0.00325) \\ t & \cdot & 0.0006 & -0.0001 \\ & & (0.00012) & (0.00046) \\ t^{2} \text { (x 100) } & \cdot & \cdot & -0.0020 \\ & & & (0.00150) \\ \text { E: Control variables } & & & \\ & & & \\ \text { Surface } & 0.0999 & 0.0994 & 0.0992 \\ & (0.0026) & (0.0025) & (0.0025) \\ \text { Surface } & & & -0.013 \\ & -0.013 & -0.013 & (0.001) \\ \text { Apartment } 1000) & (0.001) & (0.001) & -0.1714 \\ & -0.1541 & -0.1705 & (0.0094) \\ \text { Garage } & (0.0094) & (0.0094) & -0.0165 \\ & -0.0053 & -0.0155 & (0.01906)\end{array}$

Goodness of fit measures

$\begin{array}{lccc}R^{2} \text { within } & 0.6764 & 0.6825 & 0.6827 \\ R^{2} \text { between } & 0.7162 & \cdot & \cdot \\ R^{2} \text { overall } & 0.7747 & 0.7808 & 0.7819\end{array}$




\begin{tabular}{llll}
\hline \hline & I & II & III \\
\hline \hline
\end{tabular}

\section{Difference-in-difference estimators}

\begin{tabular}{|c|c|c|c|}
\hline$s$ & $\begin{array}{c}0.0037 \\
(0.00070)\end{array}$ & $\begin{array}{c}0.0074 \\
(0.00097)\end{array}$ & $\begin{array}{c}0.0109 \\
(0.00135)\end{array}$ \\
\hline \multirow[t]{2}{*}{$s^{2}$} & -0.0004 & -0.0006 & -0.0008 \\
\hline & $(0.00006)$ & $(0.00009)$ & $(0.00013)$ \\
\hline \multirow[t]{2}{*}{$s^{3}$} & 0.0000 & 0.0000 & 0.0000 \\
\hline & $(0.00000)$ & $(0.00000)$ & $(0.00000)$ \\
\hline \multirow[t]{2}{*}{$s^{4}$} & -0.0000 & -0.0000 & -0.0000 \\
\hline & $(0.00000)$ & $(0.00000)$ & $(0.00000)$ \\
\hline \multirow[t]{2}{*}{$t \times s(\mathrm{x} 100)$} & . & -0.0173 & -0.0614 \\
\hline & & $(0.00268)$ & $(0.01061)$ \\
\hline \multirow[t]{2}{*}{$t \times s^{2}(\mathrm{x} 100)$} & . & 0.0009 & 0.0035 \\
\hline & & $(0.00024)$ & $(0.00098)$ \\
\hline \multirow[t]{2}{*}{$t \times s^{3}(\mathrm{x} 100)$} & . & -0.0000 & -0.0001 \\
\hline & & $(0.00001)$ & $(0.00003)$ \\
\hline \multirow[t]{2}{*}{$t \times s^{4}(\mathrm{x} 100)$} & . & 0.0000 & 0.0000 \\
\hline & & $(0.00000)$ & $(0.00000)$ \\
\hline \multirow[t]{2}{*}{$t^{2} \times s(\mathrm{x} 1000)$} & . & . & 0.0080 \\
\hline & & & $(0.00192)$ \\
\hline \multirow[t]{2}{*}{$t^{2} \times s^{2}(\mathrm{x} 1000)$} & . & . & -0.0004 \\
\hline & & & $(0.00018)$ \\
\hline \multirow[t]{2}{*}{$t^{2} \times s^{3}(\mathrm{x} 1000)$} & . & . & 0.0000 \\
\hline & & & $(0.00001)$ \\
\hline \multirow[t]{2}{*}{$t^{2} \times s^{4}(\mathrm{x} 1000)$} & . & . & -0.0000 \\
\hline & & & $(0.00000)$ \\
\hline
\end{tabular}

\section{Other results}

Results before the murder

$\begin{array}{lccc}\text { Constant } & 11.6211 & 11.6213 & 11.6238 \\ & (0.02264) & (0.02286) & (0.02291) \\ t(\mathrm{x} \mathrm{100)} & \cdot & -0.0002 & -0.0007 \\ t^{2} & \cdot & (0.00008) & (0.00026) \\ & & \cdot & 0.0163 \\ & & & (0.00860)\end{array}$

Results before the murder, type I neighborhoods

$$
\begin{array}{cc}
0.0000 & 0.0000 \\
(0.00001) & (0.00001) \\
\cdot & -0.0000 \\
& (0.00001)
\end{array}
$$

$t^{2}(\mathrm{x} 1000)$

Results after the murder

$\begin{array}{lccc}\text { Constant } & 0.0210 & -0.0158 & -0.0297 \\ & (0.00179) & (0.00275) & (0.00379) \\ t & \cdot & 0.0017 & 0.0028 \\ & & (0.00011) & (0.00037) \\ t^{2}(\mathrm{x} 1000) & \cdot & \cdot & -0.0436 \\ & & & (0.00995)\end{array}$

Table 8: Results for the Theo van Gogh murder, second estimation method. 


\begin{tabular}{lrrr}
\hline \hline & I & \multicolumn{1}{c}{ II } & \multicolumn{1}{c}{ III } \\
\hline \hline & & & \\
Control variables & & & \\
Surface & 0.0927 & 0.0935 & 0.0934 \\
& $(0.00111)$ & $(0.00107)$ & $(0.00107)$ \\
Surface $^{2}$ (x 1000) & -0.0011 & -0.0012 & -0.0012 \\
& $(0.00003)$ & $(0.00003)$ & $(0.00003)$ \\
Apartment & -0.0994 & -0.1074 & -0.1077 \\
& $(0.00706)$ & $(0.00680)$ & $(0.00683)$ \\
Garage $^{*}$ & 0.1073 & 0.0870 & 0.0887 \\
& $(0.01355)$ & $(0.01335)$ & $(0.01337)$ \\
Goodness of fit measures & & \\
$R^{2}$ within & 0.6529 & 0.6743 & 0.6743 \\
$R^{2}$ between & 0.8378 & &. \\
$R^{2}$ overall & 0.8450 & 0.8549 & 0.8553 \\
& & & \\
\hline \hline
\end{tabular}

Table 8: Results for the Theo van Gogh murder, second estimation method. 


\begin{tabular}{|c|c|c|c|}
\hline & I & II & III \\
\hline \multicolumn{4}{|c|}{ Difference-in-difference estimators } \\
\hline $5-10$ percent & $\begin{array}{c}0.0177 \\
(0.00180)\end{array}$ & $\begin{array}{c}0.0209 \\
(0.00250)\end{array}$ & $\begin{array}{c}0.0259 \\
(0.00345)\end{array}$ \\
\hline 10-15 percent & $\begin{array}{c}-0.0157 \\
(0.00226)\end{array}$ & $\begin{array}{c}0.0106 \\
(0.00322)\end{array}$ & $\begin{array}{c}0.0225 \\
(0.00441)\end{array}$ \\
\hline $15-20$ percent & $\begin{array}{c}-0.0248 \\
(0.00307)\end{array}$ & $\begin{array}{c}0.0020 \\
(0.00436)\end{array}$ & $\begin{array}{c}0.0082 \\
(0.00592)\end{array}$ \\
\hline 20-25 percent & $\begin{array}{c}-0.0029 \\
(0.00262)\end{array}$ & $\begin{array}{c}-0.0014 \\
(0.00391)\end{array}$ & $\begin{array}{c}-0.0063 \\
(0.00524)\end{array}$ \\
\hline 25-30 percent & $\begin{array}{c}0.0049 \\
(0.00434)\end{array}$ & $\begin{array}{c}0.0029 \\
(0.00636)\end{array}$ & $\begin{array}{c}0.0136 \\
(0.00862)\end{array}$ \\
\hline 30-35 percent & $\begin{array}{c}-0.0204 \\
(0.00390)\end{array}$ & $\begin{array}{c}-0.0052 \\
(0.00590)\end{array}$ & $\begin{array}{c}-0.0075 \\
(0.00799)\end{array}$ \\
\hline $35-40$ percent & $\begin{array}{c}-0.0198 \\
(0.00327)\end{array}$ & $\begin{array}{c}0.0030 \\
(0.00501)\end{array}$ & $\begin{array}{c}0.0074 \\
(0.00655)\end{array}$ \\
\hline over 40 percent & $\begin{array}{c}-0.0004 \\
(0.00424)\end{array}$ & $\begin{array}{c}0.0115 \\
(0.00630)\end{array}$ & $\begin{array}{c}0.0003 \\
(0.00833)\end{array}$ \\
\hline$t \times 5-10$ percent $(\mathrm{x} 100)$ & . & $\begin{array}{l}-0.0297 \\
(0.00727)\end{array}$ & $\begin{array}{c}-0.0931 \\
(0.02733)\end{array}$ \\
\hline$t \times 10-15$ percent $(\mathrm{x} 100)$ & . & $\begin{array}{c}-0.1363 \\
(0.01002)\end{array}$ & $\begin{array}{c}-0.2814 \\
(0.03497)\end{array}$ \\
\hline$t \times 15-20$ percent $(\mathrm{x} 100)$ & . & $\begin{array}{c}-0.1576 \\
(0.01374)\end{array}$ & $\begin{array}{c}-0.2391 \\
(0.04677)\end{array}$ \\
\hline$t \times 20-25$ percent $(\mathrm{x} 100)$ & . & $\begin{array}{c}-0.0837 \\
(0.01426)\end{array}$ & $\begin{array}{c}-0.0392 \\
(0.04056)\end{array}$ \\
\hline$t \times 25-30$ percent $(\mathrm{x} 100)$ & . & $\begin{array}{c}-0.0876 \\
(0.02052)\end{array}$ & $\begin{array}{c}-0.2086 \\
(0.06683)\end{array}$ \\
\hline$t \times 30-35$ percent $(\mathrm{x} 100)$ & . & $\begin{array}{c}-0.1700 \\
(0.02104)\end{array}$ & $\begin{array}{c}-0.1372 \\
(0.06261)\end{array}$ \\
\hline$t \times 35-40$ percent $(\mathrm{x} 100)$ & . & $\begin{array}{c}-0.2075 \\
(0.02061)\end{array}$ & $\begin{array}{c}-0.2408 \\
(0.05270)\end{array}$ \\
\hline$t \times$ over 40 percent $(\mathrm{x} 100)$ & . & $\begin{array}{l}-0.1859 \\
(0.02475)\end{array}$ & $\begin{array}{l}-0.0292 \\
(0.06528)\end{array}$ \\
\hline$t^{2} \times 5-10$ percent $(\mathrm{x} 1000)$ & . & $\cdot$ & $\begin{array}{c}0.0118 \\
(0.00498)\end{array}$ \\
\hline$t^{2} \times 10-15$ percent $(x 1000)$ & . & . & $\begin{array}{c}0.0278 \\
(0.00636)\end{array}$ \\
\hline$t^{2} \times 15-20$ percent $(\mathrm{x} 1000)$ & . & . & $\begin{array}{c}0.0168 \\
(0.00846)\end{array}$ \\
\hline$t^{2} \times 20-25$ percent $(x 1000)$ & . & . & $\begin{array}{c}-0.0045 \\
(0.00727)\end{array}$ \\
\hline$t^{2} \times 25-30$ percent $(\times 1000)$ & . & . & $\begin{array}{c}0.0286 \\
(0.01206)\end{array}$ \\
\hline$t^{2} \times 30-35$ percent $(\mathrm{x} 1000)$ & . & . & $\begin{array}{c}0.0032 \\
(0.01137)\end{array}$ \\
\hline$t^{2} \times 35-40$ percent $(\times 1000)$ & . & . & $\begin{array}{c}0.0178 \\
(0.00981)\end{array}$ \\
\hline$t^{2} \times$ over 40 percent $(\mathrm{x} 1000)$ & . & . & $\begin{array}{c}-0.0114 \\
(0.01187)\end{array}$ \\
\hline
\end{tabular}

Table 9: Results for the Theo van Gogh murder, second estimation method. 


\begin{tabular}{llll}
\hline \hline I & II & III \\
\hline
\end{tabular}

Other results

Results before the murder

$\begin{array}{lrrr}\text { Constant } & 11.6154 & 11.6070 & 11.6111 \\ & (0.02252) & (0.02262) & (0.02264) \\ t(\mathrm{x} 100) & \cdot & -0.0002 & -0.0006 \\ t^{2} & \cdot & (0.00008) & (0.00023) \\ & & \cdot & 0.0134 \\ & & & (0.00805)\end{array}$

Results before the murder, type I neighborhoods

$t^{2}(\mathrm{x} 1000)$

$0.0000 \quad 0.0000$

$(0.00000) \quad(0.00001)$

$-0.0000$

$(0.00000)$

Results after the murder

Constant

$$
\begin{array}{r}
0.0256 \\
(0.00096)
\end{array}
$$

$-0.0052$

$-0.0102$

$t$

$(0.00167) \quad(0.00233)$

$0.0014 \quad 0.0014$

$(0.00008) \quad(0.00028)$

Control variables

$t^{2}(\mathrm{x} 1000)$

$-0.0215$

Surface

0.0930

0.0943

(0.00849)

Surface $^{2}$ (x 1000)

$-0.0011$

(0.00108)

(0.00108)

Apartment

$(0.00003)$

$-0.0012$

$-0.0012$

$-0.0972$

$-0.0999$

(0.00003)

Garage

$(0.00710)$
0.1089

$(0.00691)$

(0.00694)

$(0.01352)-(0.01312)$

Goodness of fit measures

$\begin{array}{lrrr}R^{2} \text { within } & 0.6526 & 0.6752 & 0.6749 \\ R^{2} \text { between } & 0.8339 & \cdot & . \\ R^{2} \text { overall } & 0.8451 & 0.8565 & 0.8566\end{array}$

Table 9: Results for the Theo van Gogh murder, second estimation method. 


\section{Table 10: Results using conditionally sold houses}

This table shows the neighborhood-effects using only the houses that are ultimately conditionally sold. The first column lists the estimation results for the specification of $\lambda(t)=c$. The second and third column list the estimation results for the linear and quadratic specification, respectively. Panel A gives the diff-in-diff estimates. Panel B to D show the estimation results for the general price effect before the murder, before the murder in type I neighborhoods, and after the murder. The variables $\eta, \pi, \zeta$, and $\omega$ refer to the variables defined in Equation (8).

\begin{tabular}{llll}
\hline \hline & I & II & III \\
\hline
\end{tabular}

\section{A: Difference-in-difference estimators}

$\begin{array}{lccc}\text { Constant } & -0.0081 & 0.0061 & -0.0039 \\ & (0.0031) & (0.0063) & (0.0092) \\ t & \cdot & -0.0023 & -0.0044 \\ & & (0.0003) & (0.0013) \\ t^{2}(\mathrm{x} 100) & \cdot & \cdot & -0.0075 \\ & & & (0.0041)\end{array}$

Other results

B: Results before the murder

$\begin{array}{lccc}t & 11.59 & 11.58 & 11.58 \\ & (0.024) & (0.024) & (0.024) \\ t^{2}(\mathrm{x} 100) & \cdot & -0.0005 & 0.0003 \\ & & (0.0001) & (0.0004) \\ \text { Constant } & \cdot & \cdot & -0.0030 \\ & & & (0.0014)\end{array}$

C: Results before the murder, type I neighborhoods

$$
\begin{array}{cc}
0.0011 & -0.0008 \\
(0.0003) & (0.0011) \\
\cdot & 0.0075 \\
& (0.0040)
\end{array}
$$

$t^{2}(\mathrm{x} 100)$

D: Results after the murder

$\begin{array}{lccc}\text { Constant } & 0.0224 & 0.0055 & 0.0014 \\ & (0.0011) & (0.0022) & (0.0032) \\ t & \cdot & 0.0014 & 0.0031 \\ & & (0.0001) & (0.0004) \\ t^{2}(\mathrm{x} 100) & \cdot & \cdot & 0.0013 \\ & & & (0.0014) \\ \text { E: Control variables } & & & \\ & & & \\ \text { Surface } & 0.0907 & 0.0919 & 0.0920 \\ & (0.00109) & (0.00109) & (0.00109) \\ \text { Surface } & & & -0.010 \\ & -0.010 & -0.010 & -0.0003) \\ \text { Apartment } 1000) & (0.0003) & (0.0003) & (0.0003) \\ & -0.0463 & -0.0470 & -0.0441 \\ \text { Garage } & (0.00750) & (0.00746) & (0.0075) \\ & 0.1026 & 0.1077 & 0.1082 \\ & (0.01290) & (0.01284) & (0.0128)\end{array}$

Goodness of fit measures

$\begin{array}{lllc}R^{2} \text { within } & 0.6510 & 0.6573 & 0.6581 \\ R^{2} \text { between } & 0.8152 & 0.7694 & \cdot \\ R^{2} \text { overall } & 0.8036 & 0.8072 & 0.8079\end{array}$




\section{Table 11: Estimation results for the duration model}

The variables $v_{0}$ and $v_{1}$ are mass points of the unobserved heterogeneity distribution and $p$ is the probability that the unobserved heterogeneity term equals $v_{0}$.

\begin{tabular}{|c|c|}
\hline $\begin{array}{l}\text { Variable } \\
\end{array}$ & Estimate \\
\hline \multicolumn{2}{|l|}{ House characteristics } \\
\hline Square footage & $\begin{array}{r}-0.0035 \\
(0.0004)\end{array}$ \\
\hline Square footage $^{2}(\mathrm{x} 1000)$ & $\begin{array}{r}0.0027 \\
(0.0006)\end{array}$ \\
\hline Apartment & $\begin{array}{l}-0.171 \\
(0.043)\end{array}$ \\
\hline Garage attached & $\begin{array}{l}-0.178 \\
(0.088)\end{array}$ \\
\hline \multicolumn{2}{|l|}{ Time effects } \\
\hline $1^{s t}$ quarter before the murder & $\begin{array}{r}0.057 \\
(0.065)\end{array}$ \\
\hline $1^{s t}$ quarter after the murder & $\begin{array}{r}0.032 \\
(0.064)\end{array}$ \\
\hline $2^{\text {nd }}$ quarter after the murder & $\begin{array}{r}0.275 \\
(0.062)\end{array}$ \\
\hline $3^{r d}$ quarter after the murder & $\begin{array}{r}0.213 \\
(0.061)\end{array}$ \\
\hline $4^{\text {th }}$ quarter after the murder & $\begin{array}{r}0.321 \\
(0.062)\end{array}$ \\
\hline \multicolumn{2}{|c|}{ Time effects $\times$ type I neighborhoods } \\
\hline $1^{\text {st }}$ quarter before the murder & $\begin{array}{r}0.315 \\
(0.215)\end{array}$ \\
\hline $1^{s t}$ quarter after the murder & $\begin{array}{r}0.416 \\
(0.210)\end{array}$ \\
\hline $2^{\text {nd }}$ quarter after the murder & $\begin{array}{r}0.345 \\
(0.207)\end{array}$ \\
\hline $3^{\text {rd }}$ quarter after the murder & $\begin{array}{r}0.294 \\
(0.207)\end{array}$ \\
\hline $4^{\text {th }}$ quarter after the murder & $\begin{array}{r}0.315 \\
(0.207)\end{array}$ \\
\hline \multicolumn{2}{|c|}{ Duration dependence, baseline: weeks 1-4 } \\
\hline Weeks $5-8$ & $\begin{array}{r}1.131 \\
(0.052)\end{array}$ \\
\hline Weeks 9-13 & $\begin{array}{r}1.611 \\
(0.050)\end{array}$ \\
\hline $2^{\text {nd }}$ quarter & $\begin{array}{r}1.502 \\
(0.049)\end{array}$ \\
\hline $3^{r d}$ quarter & $\begin{array}{r}1.415 \\
(0.056)\end{array}$ \\
\hline $4^{\text {th }}$ quarter & $\begin{array}{r}1.339 \\
(0.067)\end{array}$ \\
\hline After $4^{t h}$ quarter & $\begin{array}{r}1.346 \\
(0.087)\end{array}$ \\
\hline \multicolumn{2}{|l|}{ Unobserved heterogeneity } \\
\hline$v_{0}$ & $\begin{array}{r}-4.734 \\
(0.178)\end{array}$ \\
\hline$v_{1}$ & - \\
\hline$p$ & $\begin{array}{r}1 \\
(\cdot)\end{array}$ \\
\hline
\end{tabular}


Table 12: Descriptive statistics for the register database.

This table gives the number of houses, mean and standard deviation of the transactions as registered in the 'Kadaster', the Dutch register for (residential) property. Only houses that have been listed on Funda are included. 'Listed price' is the last price recorded on Funda, the online multi-listing service and our primary source of data. 'Registered price' is the transaction price as registerd by the Kadaster. 'Discount' is the difference between the list price and transaction price.

\begin{tabular}{|c|c|c|c|}
\hline Variable & Mean & $\begin{array}{l}\text { Number of } \\
\text { observations }\end{array}$ & $\begin{array}{l}\text { Standard } \\
\text { deviation }\end{array}$ \\
\hline
\end{tabular}

All neigborhoods

$\begin{array}{lrrr}\text { Listed price } & 270609 & 10480 & 189267 \\ \text { Registered price } & 259526 & 10480 & 177453 \\ \text { Discount } & 4.17 \% & 10480 & 4.74 \%\end{array}$

Type I-neighborhoods

$\begin{array}{lrrr}\text { Listed price } & 171930 & 1366 & 50620 \\ \text { Registered price } & 165649 & 1366 & 52730 \\ \text { Discount } & 3.82 \% & 1366 & 4.05 \%\end{array}$

Type II-neighborhoods

\begin{tabular}{lrrr} 
Listed price & 285399 & 9114 & 197728 \\
Registered price & 273596 & 9114 & 185221 \\
Discount & $4.23 \%$ & 9114 & $4.83 \%$ \\
\hline \hline
\end{tabular}

\begin{tabular}{lrrrr}
\hline \hline & Total & Before murder & After murder & \multicolumn{2}{c}{$\begin{array}{c}\text { t-value } \\
\text { of difference }\end{array}$} \\
\hline \hline Buyers & 0.0929 & 0.0812 & 0.0987 & 1.88 \\
& $(0.0045)$ & $(0.0074)$ & $(0.0056)$ & \\
Sellers & 0.0425 & 0.0514 & 0.0375 & -1.64 \\
& $(0.0039)$ & $(0.0071)$ & $(0.0046)$ & \\
\hline \hline
\end{tabular}

Table 13: Fraction of buyers and sellers with Turkish or Moroccan origin.

\begin{tabular}{lrrrr}
\hline \hline & Total & Before murder & After murder & $\begin{array}{c}\text { t-value } \\
\text { of difference }\end{array}$ \\
\hline \hline Buyers & 0.0197 & 0.0188 & 0.0204 & 0.31 \\
& $(0.0026)$ & $(0.0041)$ & $(0.0035)$ & \\
Sellers & 0.0059 & 0.0081 & 0.0042 & -1.16 \\
& $(0.0016)$ & $(0.0029)$ & $(0.0019)$ & \\
\hline \hline
\end{tabular}

Table 14: Fraction of buyers and sellers with Turkish or Moroccan origin. 


\begin{tabular}{lrr}
\hline \hline Type I & Type II & $\begin{array}{r}\text { Outside } \\
\text { Amsterdam }\end{array}$ \\
\hline \hline
\end{tabular}

Before the murder

\begin{tabular}{lrrr} 
Turkish or Moroccan & 0.330 & 0.491 & 0.179 \\
& $(0.061)$ & $(0.063)$ & $(0.050)$ \\
Non Turkish or Moroccan & 0.188 & 0.254 & 0.558 \\
& $(0.014)$ & $(0.015)$ & $(0.017)$ \\
& & & \\
After the murder & & & \\
Turkish or Moroccan & 0.332 & 0.224 & 0.444 \\
& $(0.038)$ & $(0.037)$ & $(0.042)$ \\
Non Turkish or Moroccan & 0.152 & 0.285 & 0.563 \\
& $(0.010)$ & $(0.012)$ & $(0.014)$ \\
\hline \hline
\end{tabular}

Table 15: Percentages of buyers' origin state before and after the murder, type I neighborhoods.

\begin{tabular}{lrr}
\hline \hline Type I & Type II & $\begin{array}{r}\text { Outside } \\
\text { Amsterdam }\end{array}$ \\
\hline \hline
\end{tabular}

Before the murder

$\begin{array}{lrrr}\text { Turkish or Moroccan } & 0.095 & 0.667 & 0.238 \\ & (0.019) & (0.048) & (0.040) \\ \text { Non Turkish or Moroccan } & 0.058 & 0.415 & 0.527 \\ & (0.002) & (0.007) & (0.008)\end{array}$

After the murder

\begin{tabular}{lrrr} 
Turkish or Moroccan & 0.061 & 0.364 & 0.576 \\
& $(0.010)$ & $(0.040)$ & $(0.043)$ \\
Non Turkish or Moroccan & 0.029 & 0.450 & 0.521 \\
& $(0.0001)$ & $(0.006)$ & $(0.006)$ \\
\hline \hline
\end{tabular}

Table 16: Percentages of buyers' origin state before and after the murder, type II neighborhoods 


\begin{tabular}{lrr}
\hline \hline Type I & Type II & $\begin{array}{r}\text { Outside } \\
\text { Amsterdam }\end{array}$ \\
\hline \hline
\end{tabular}

Before the murder

\begin{tabular}{lrrr} 
Turkish or Moroccan & 0.232 & 0.372 & 0.395 \\
& $(0.088)$ & $(0.099)$ & $(0.099)$ \\
Non Turkish or Moroccan & 0.173 & 0.266 & 0.561 \\
& $(0.016)$ & $(0.018)$ & $(0.021)$ \\
& & & \\
After the murder & & & \\
Turkish or Moroccan & 0.479 & 0.229 & 0.292 \\
Non Turkish or Moroccan & $(0.100)$ & $(0.090)$ & $(0.085)$ \\
& $(0.015)$ & 0.242 & 0.608 \\
& & $(0.015)$ & $(0.017)$ \\
\hline \hline
\end{tabular}

Table 17: Percentages of sellers' destination state before and after the murder, type I neighborhoods

\begin{tabular}{lrr}
\hline \hline Type I & Type II & $\begin{array}{r}\text { Outside } \\
\text { Amsterdam }\end{array}$ \\
\hline \hline
\end{tabular}

Before the murder

$\begin{array}{lrrr}\text { Turkish or Moroccan } & 0.000 & 0.556 & 0.444 \\ & (0.000) & (0.082) & (0.082) \\ \text { Non Turkish or Moroccan } & 0.015 & 0.473 & 0.512 \\ & (0.0004) & (0.008) & (0.008)\end{array}$

After the murder

\begin{tabular}{lrrr} 
Turkish or Moroccan & 0.000 & 0.143 & 0.857 \\
& $(0.000)$ & $(0.046)$ & $(0.046)$ \\
Non Turkish or Moroccan & 0.016 & 0.444 & 0.540 \\
& $(0.0004)$ & $(0.007)$ & $(0.017)$ \\
\hline \hline
\end{tabular}

Table 18: Percentages of sellers' destination state before and after the murder, type II neighborhoods 
Table 19: Results of the block bootstrap exercise

\begin{tabular}{lccc}
\hline \hline \multicolumn{1}{c}{ I } & II & III \\
\hline \hline \multirow{2}{*}{ Actual levels } & & & \\
& & & \\
Constant & -5.657 & -0.782 & -1.808 \\
$t$ & & -6.428 & -2.976 \\
$t^{2}$ & & & -1.839
\end{tabular}

Bootstrap critical values at different significant levels

\section{Constant}

1 percent $\quad-10.296 \quad-9.761 \quad-5.399$

5 percent $\quad-7.733 \quad-7.385-4.194$

10 percent $\quad-6.289 \quad-6.698 \quad-3.802$

Coefficient for $t$

$\begin{array}{lll}1 \text { percent } & -5.981 & -4.439 \\ 5 \text { percent } & -4.014 & -3.270 \\ 10 \text { percent } & -3.333 & -2.789\end{array}$

Coefficient for $t^{2}$

$\begin{array}{ll}1 \text { percent } & -3.459 \\ 5 \text { percent } & -2.483 \\ 10 \text { percent } & -1.974\end{array}$




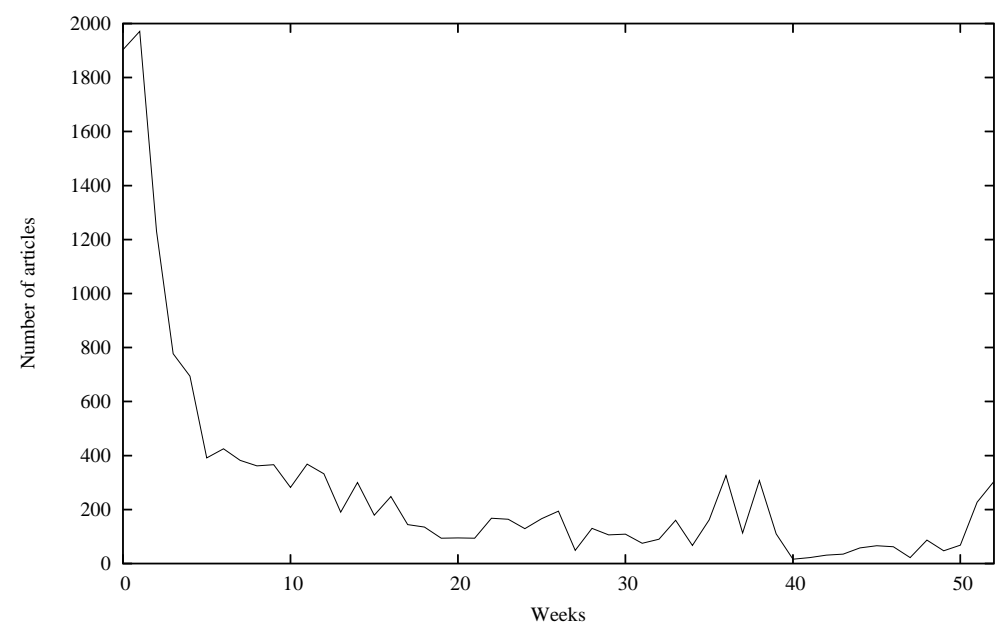

Figure 1: Newspaper articles per week mentioning the murder.

This figure displays for any given week the number of newspaper articles found in all Dutch news sources on LexisNexis, that had the words 'Gogh' and 'moord' in one sentence. The unit at the $x$-axis is the number of weeks starting from the first week in 2004 .

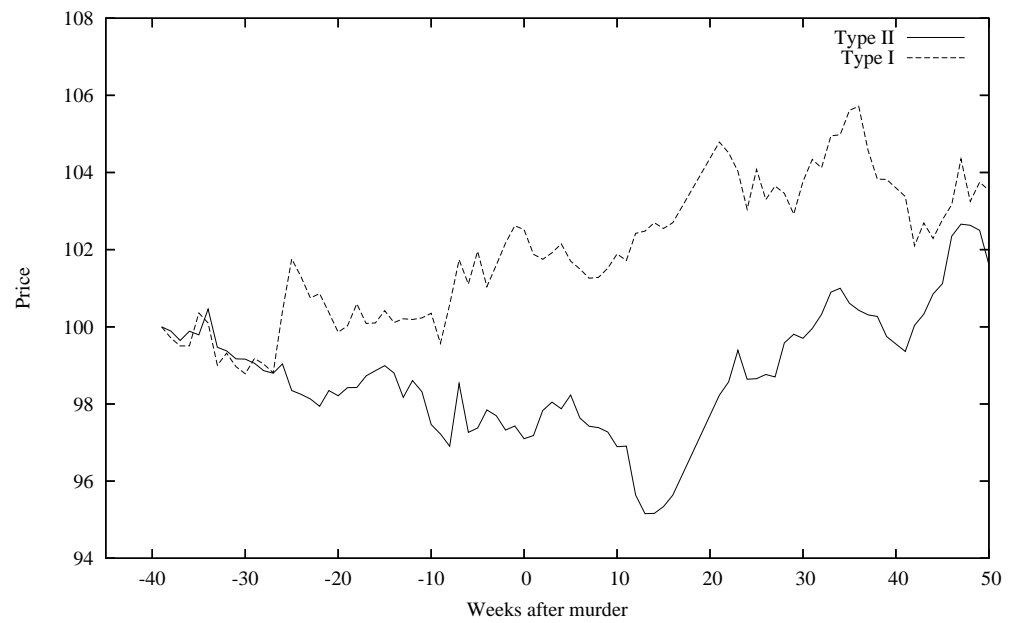

Figure 2: Development of house prices in Amsterdam.

The $y$-axis is measured as an index which equals 100 in week 6 of 2004 for both neighborhood types. 


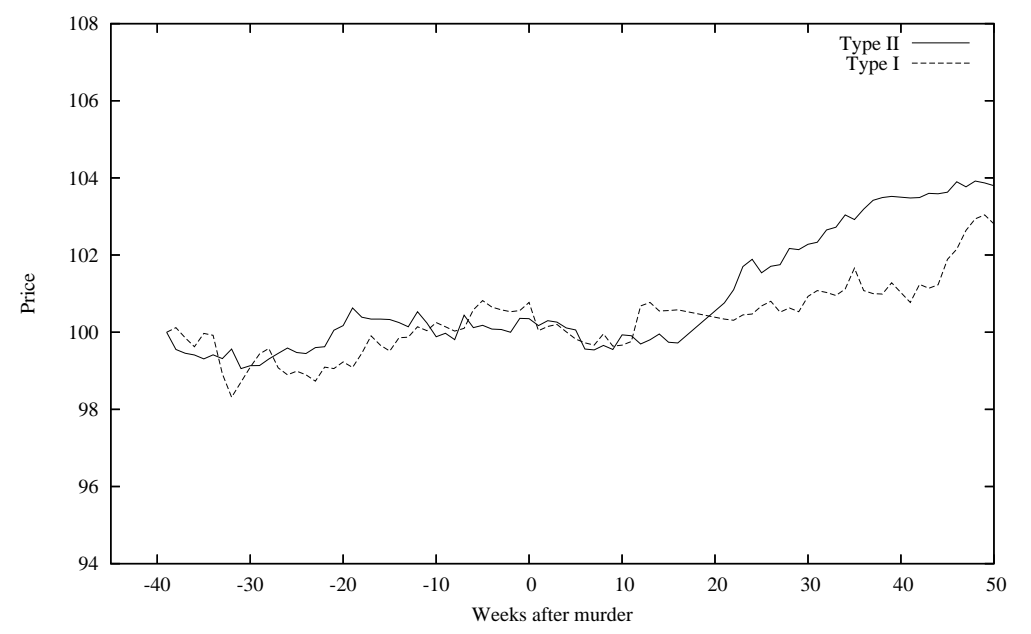

Figure 3: Development of square footage prices in Amsterdam.

The $y$-axis is measured as an index which equals 100 in week 6 of 2004 for both neighborhood types.

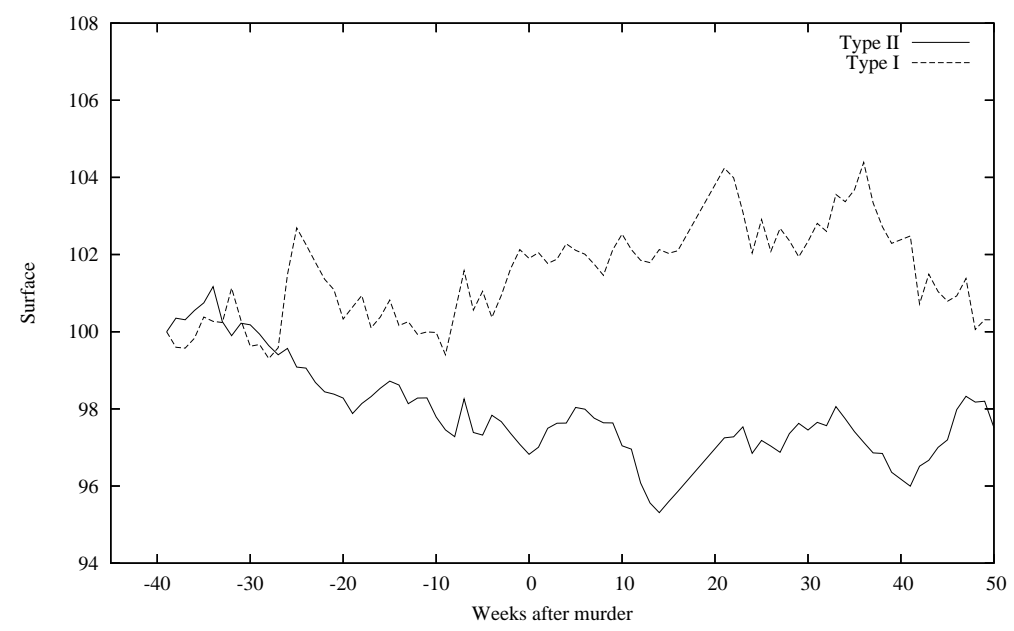

Figure 4: Development of square footage in Amsterdam.

The $y$-axis is measured as an index which equals 100 in week 6 of 2004 for both neighborhood types. 

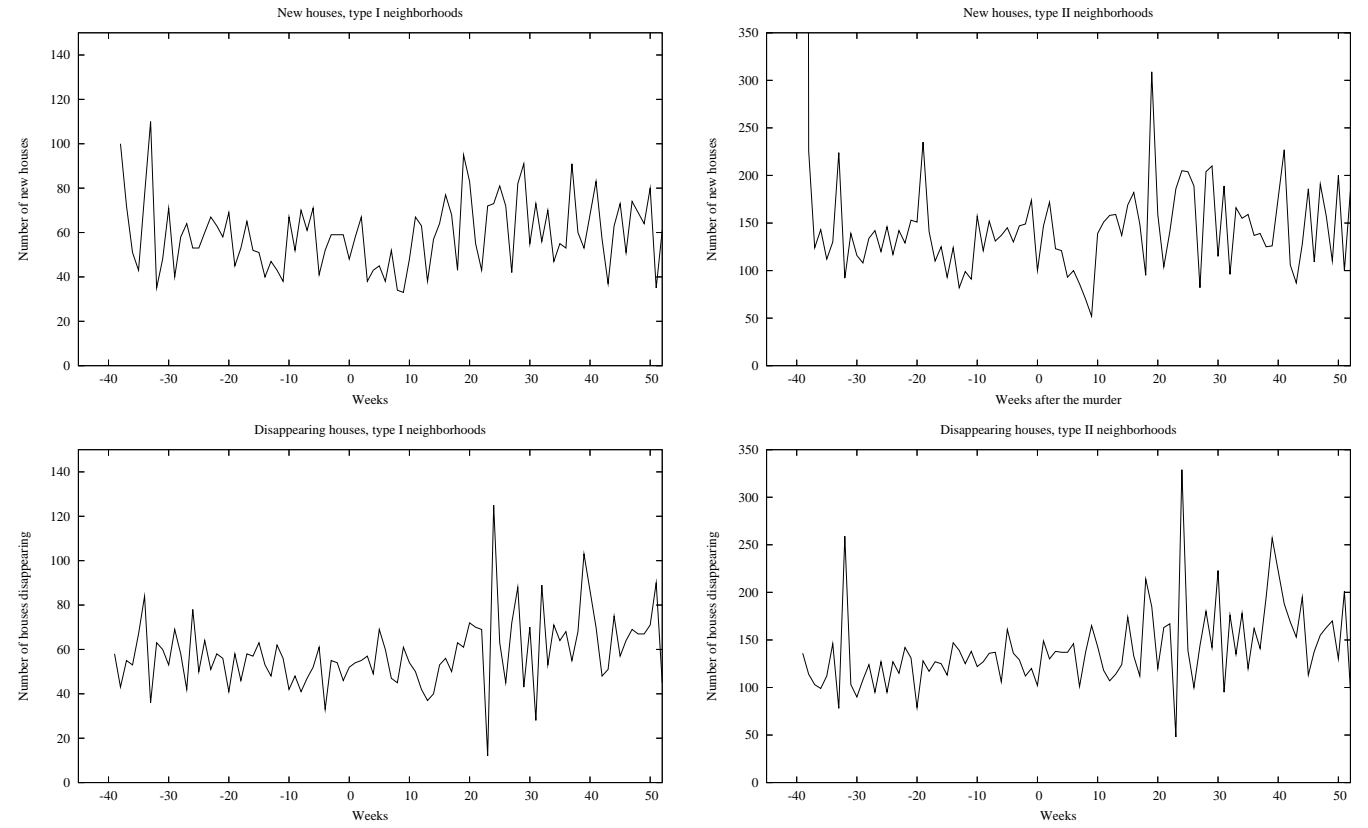

Figure 5: Development of in and outflow of new houses at the Funda website

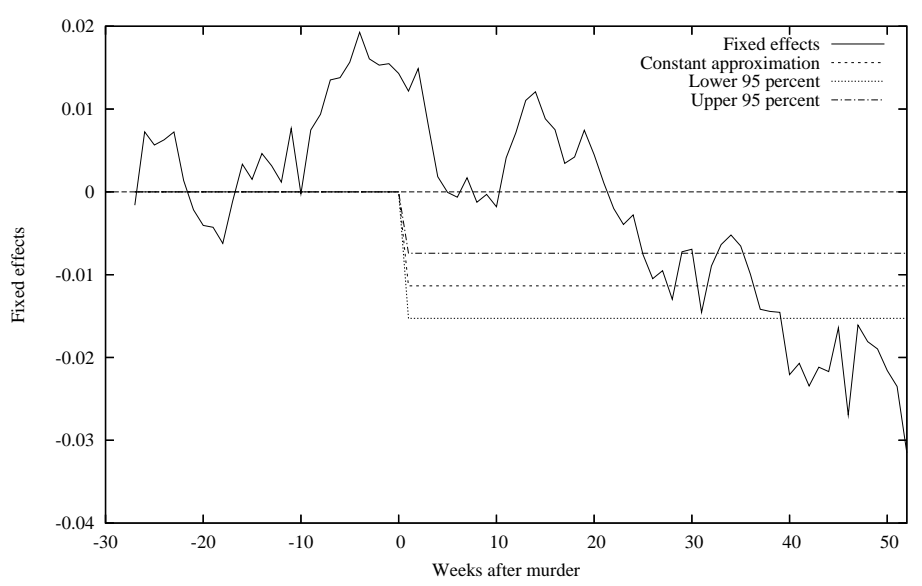

Figure 6: Quality of the approximation: the constant model.

This figure shows the results for the fixed effects estimation (solid line) together with the result for the approximating constant model (dashed line). 


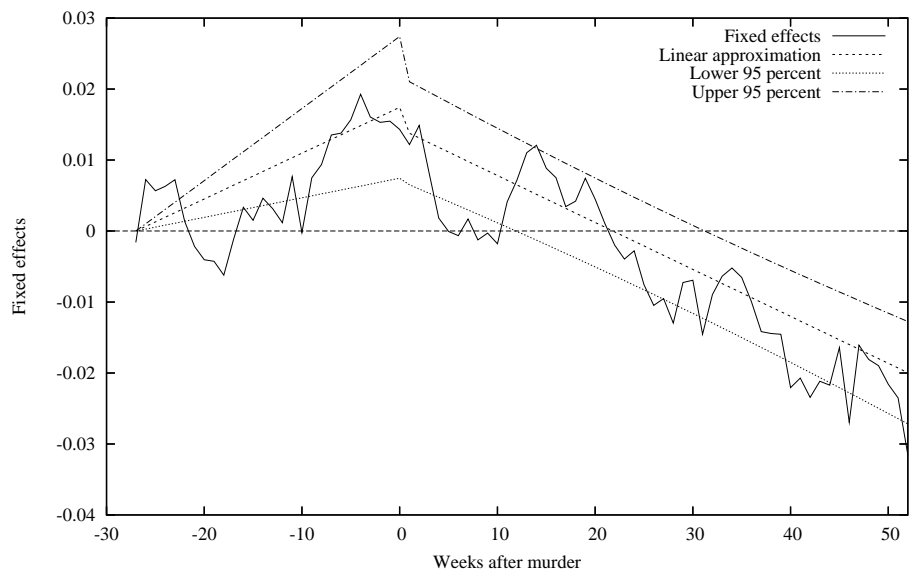

Figure 7: Quality of the approximation: the linear model.

This figure shows the estimation results for the linear model, together with the $95 \%$ confidence bands.

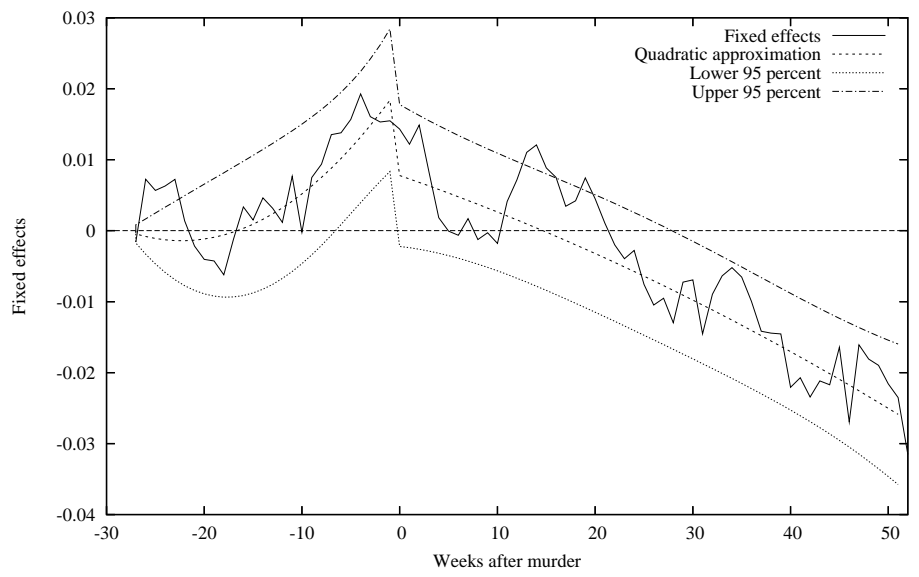

Figure 8: Quality of the approximation: the quadratic model. This figure shows the estimation results for the quadratic model, together with the $95 \%$ confidence bands. 


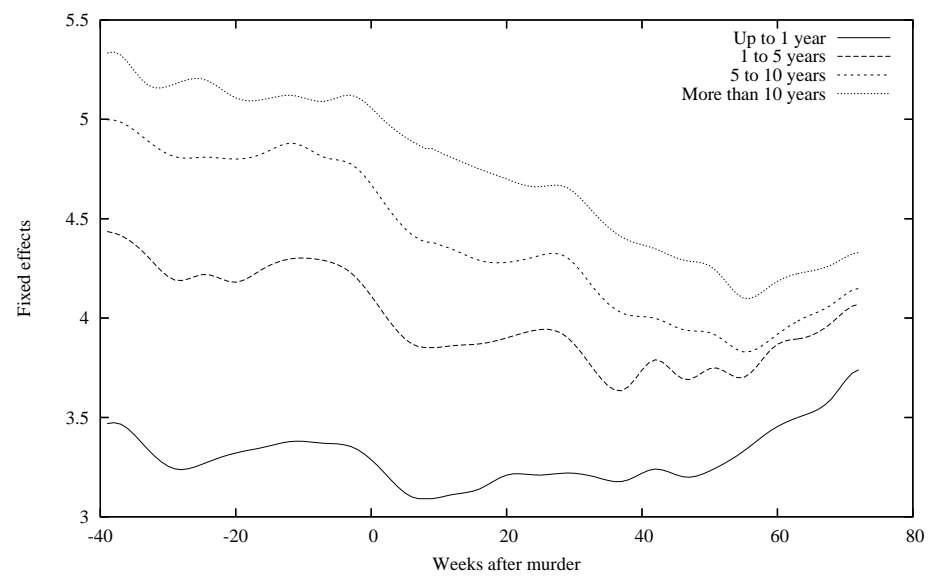

Figure 9: Interest rates over time.

This figure shows the interest rates over time. Source is the Netherlands Central Bank (DNB). Original data is on a monthly basis. We used cubic splines to obtain data on a weekly basis.

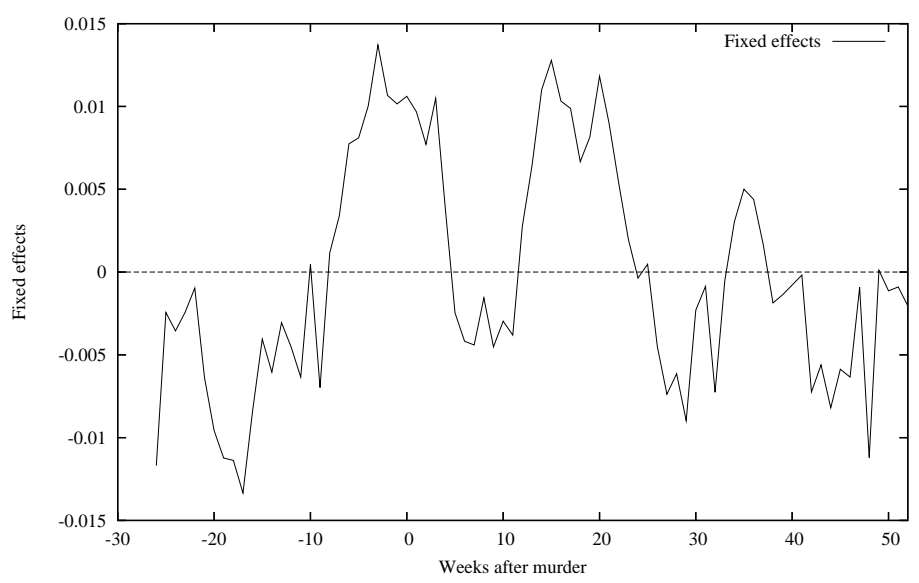

Figure 10: Residuals of the fixed effects regression over time.

This figure shows the residuals of estimated fixed effect on the interest rate over time. 


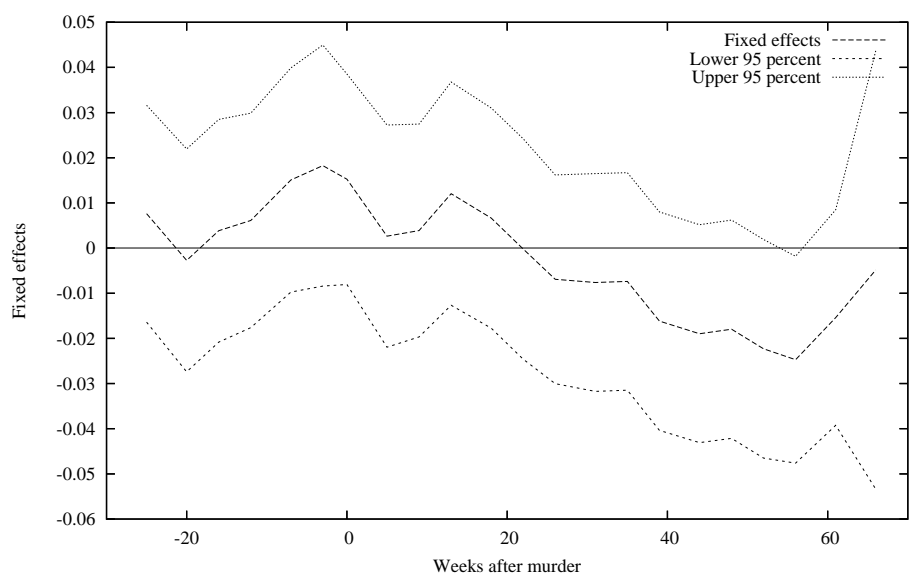

Figure 11: Regression based on 1st week prices.

This figure shows the estimation results for the quadratic model, together with the $95 \%$ confidence bands.

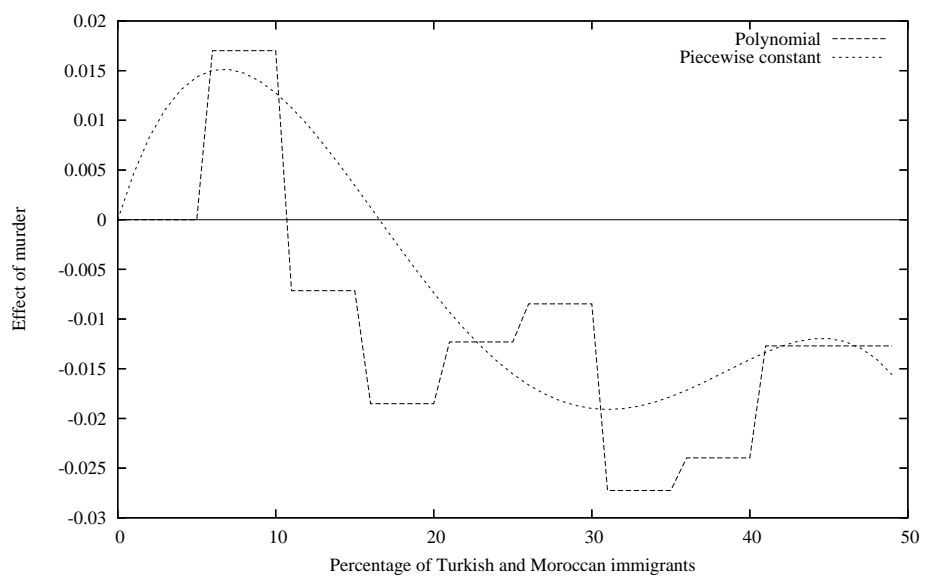

Figure 12: The impact of the murder after 13 weeks. This figure shows ... 


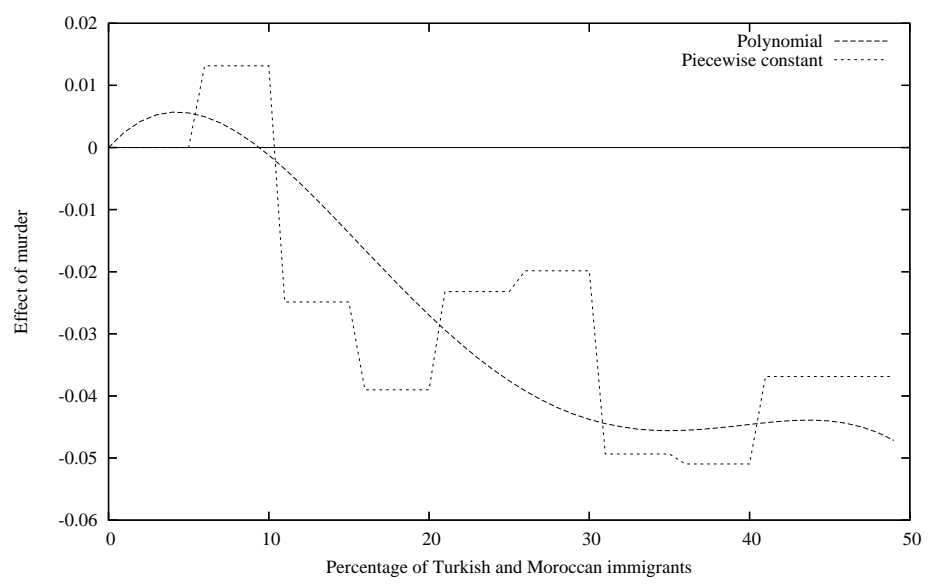

Figure 13: The impact of the murder after $\mathbf{2 6}$ weeks. This figure shows ...

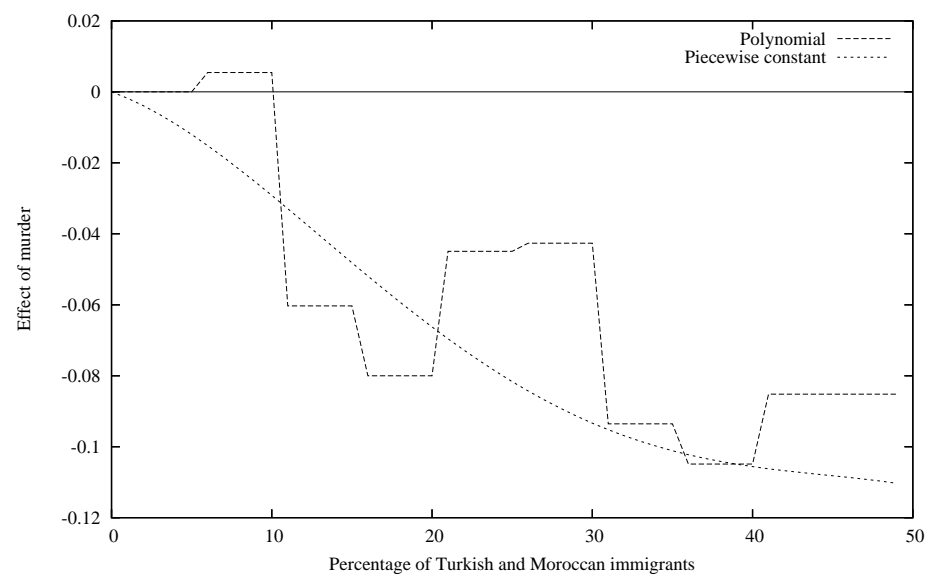

Figure 14: The impact of the murder after 52 weeks. This figure shows ... 


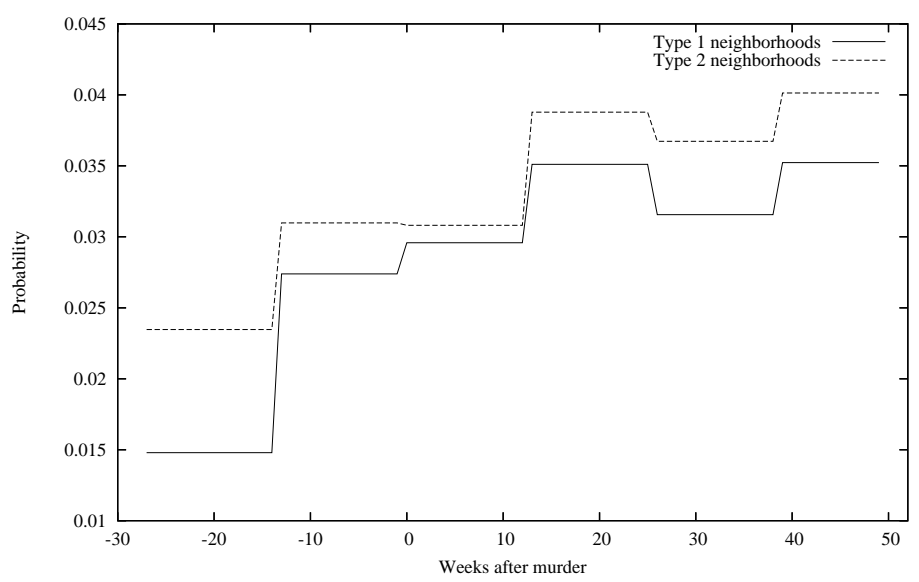

Figure 15: Hazard rates.

This figure shows the hazard rates of a house disappearing from the market. The values in the graph can be interpreted as the probability to sell in the first week. The unit at the $x$-axis is the number of weeks starting from the first week in 2004 .

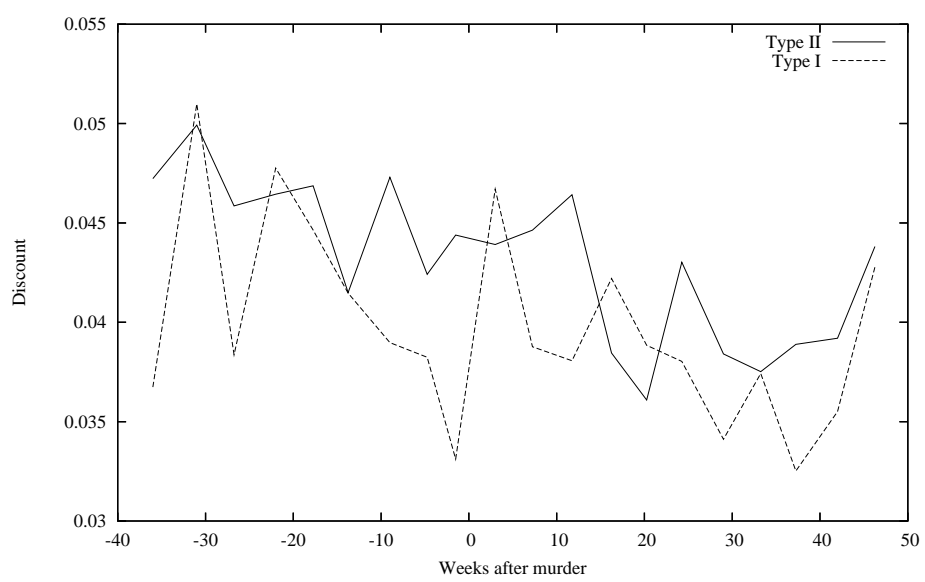

Figure 16: Average discount over time

This figure shows the average discount between transaction price and list price. The discount is computed per month. 


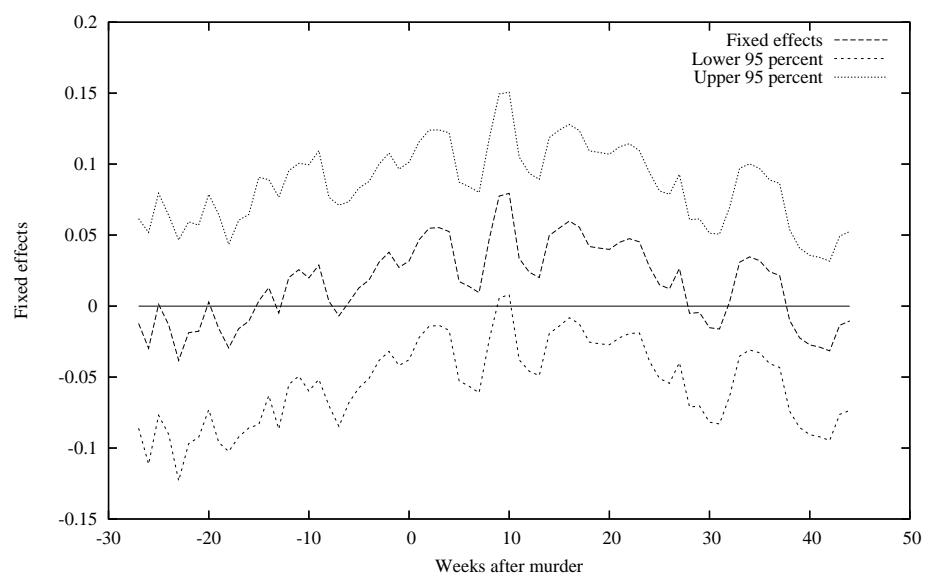

Figure 17: Results for Rotterdam 